\title{
Etnônimos e topônimos no Madeira (séculos XVI-XX): um sem-número de equívocos
}

\author{
Henri Ramirez ${ }^{1}$
}

\begin{abstract}
Resumo
Talvez seja urgente chamar a atenção sobre alguns problemas significativos na literatura que se referem aos etnônimos e à cartografia do Rio Madeira (Brasil e Bolívia). Apesar das boas observações contidas no Handbook of South American Indians (1948), certas revisões são necessárias para dar conta dos problemas que apresentamos. Este artigo reconsidera e corrige os etnônimos que se tornaram confusos no século passado. Utiliza essas revisões para refazer o mapa histórico dos povos indígenas da região. Os erros que foram perpetuados nos registros históricos, assim como o ritmo acelerado da aculturação, apontam para uma urgente necessidade de novos estudos etno-históricos na região.
\end{abstract}

Palavras-chave: Rio Madeira, etno-história, equívocos sobre etnônimos, mapas, glossário.

\begin{abstract}
It is perhaps urgent to call attention to significant problems in the literature concerning ethnonyms and cartography for the Madeira River (Brazil and Bolivia). Though the Handbook of South American Indians (1948) provides a useful overview of the region, certain revisions are necessary to the account presented there. This paper reviews and revises a number of ethnonyms that have resulted in confusion over the past century. The paper uses these revisions to redraw the historical map of indigenous peoples in the region. In view of the errors that have been perpetuated in the historical record and given the rapid pace of acculturation, there is an urgent need for new ethno-historical studies in the region.
\end{abstract}

Keywords: Madeira river, ethno-history, misleading ethnonyms, maps, glossary.

"As etnografias históricas pioneiras de Alfred Métraux, aparecidas no Handbook of South American Indians, depois de quarenta e cinco anos, não mostram necessidade de revisão." (Block 1997:34).

\section{Introdução}

No decurso destes últimos anos, investigamos o passado do que chamaremos doravante a região "Grande Madeira" (entre o Purus e o Tapajós). A ideia foi motivada pelos inúmeros equívocos entre as denominações antigas e os etnônimos atuais das populações indígenas, e também pela

\footnotetext{
${ }^{1}$ Professor de Linguística na Universidade Federal de Rondônia, Brasil (henriramirez@uol.com.br)
} 
simples observação de Block acima epigrafada. Neste trabalho², tentaremos responder a três perguntas: as monografias do Handbook of South American Indians (HSAI) referentes à Grande Madeira precisam ou não de revisão? Como surgiram e se criaram tantos equívocos de etnônimos? O que, depois da publicação do HSAI, foi feito para retificar isso? A última pergunta já pode ser respondida: nada ou quase nada.

Avaliaremos apenas algumas monografias do HSAI publicado por Steward (1948): os etnônimos da família Chapacura, assim como a história das palavras "guarayo", "cawahib", "parintintin", "cinta larga", "nambiquara”, "rikbaktsa", "caripuna", "pacaás-novos" e "mequéns". Mas, antes de tudo, um pouco de geografia!

\section{2. $O$ grande Madeira}

O maior afluente do Amazonas e um dos rios mais volumosos do mundo, com mais de $3.300 \mathrm{~km}$ de extensão, o Madeira já tem uma descarga de $17.600 \mathrm{~m}^{3} / \mathrm{s}$ na junção de seus formadores (cf. Fig. 1). Acima da cidade de Porto Velho, o Madeira apresenta um longo trecho encachoeirado.

As cabeceiras do Madeira ainda constituem um problema: qual de seus formadores - o Beni, o Madre de Dios, o Mamoré ou o Guaporé-Itenes - seria o verdadeiro Madeira? Esses rios nascem nos Andes bolivianos ou peruanos, exceto o Guaporé-Itenes que nasce no Brasil. Quanto à descarga fluvial, o Madre de Dios tem a maior vazão, seguido pelo Mamoré. No entanto, o Mamoré e o Itenes drenam $567.860 \mathrm{~km}^{2}$, uma área duas vezes maior que a do Beni e do Madre de Dios. Quanto ao comprimento, é o rio San Miguel (1.200 $\mathrm{km})$, afluente do Guaporé-Itenes, que ganha dos outros. Com o nome de Parapetí, com suas cabeceiras nos Andes perto de Pomabamba, o San Miguel se dirige mais adiante para o norte. Segue seu curso no norte do Chaco e atravessa os banhados do Izozog. Desde este ponto, segue sempre para o norte com o nome de Quimome, chamando-se sucessivamente San Miguel, San Julián, San Pablo, San Luís e Itonama, até desembocar no GuaporéItenes. Apesar de seu comprimento, em muitos trechos o San Miguel é um rio estreito e quase sem água na época da estiagem.

Extremamente diversificada, a paisagem que predomina no Madeira é a luxuriante floresta amazônica. Os Pampas de Moxos formam grandes

\footnotetext{
${ }^{2}$ Meus sinceros agradecimentos a Aryon Dall'Igna Rodrigues, Ana Suelly Cabral, Gilles de Catheu, Glenn Shepard e Hein van der Voort por seus comentários. Os erros encontrados neste trabalho sendo da inteira responsabilidade do autor.
} 
savanas, em parte alagadas na época das chuvas. Ao sueste, o vale do Madeira é delimitado pelo cerrado de Mato Grosso (aproximadamente até $10^{\circ}$ lat. S.), pela flora de transição de Santa Cruz e da Chiquitanía e pelas pastagens e desertos do Chaco.

\subsection{Os mapas}

As figuras 2 e 3 mostram a localização das etnias indígenas na época do primeiro contato. As informações no alto Madeira são numerosas durante os séculos XVI e XVII, mas o interflúvio Madeira-Tapajós só começa a ser entendido no século XVIII. Essa disparidade deve-se à lógica dos movimentos

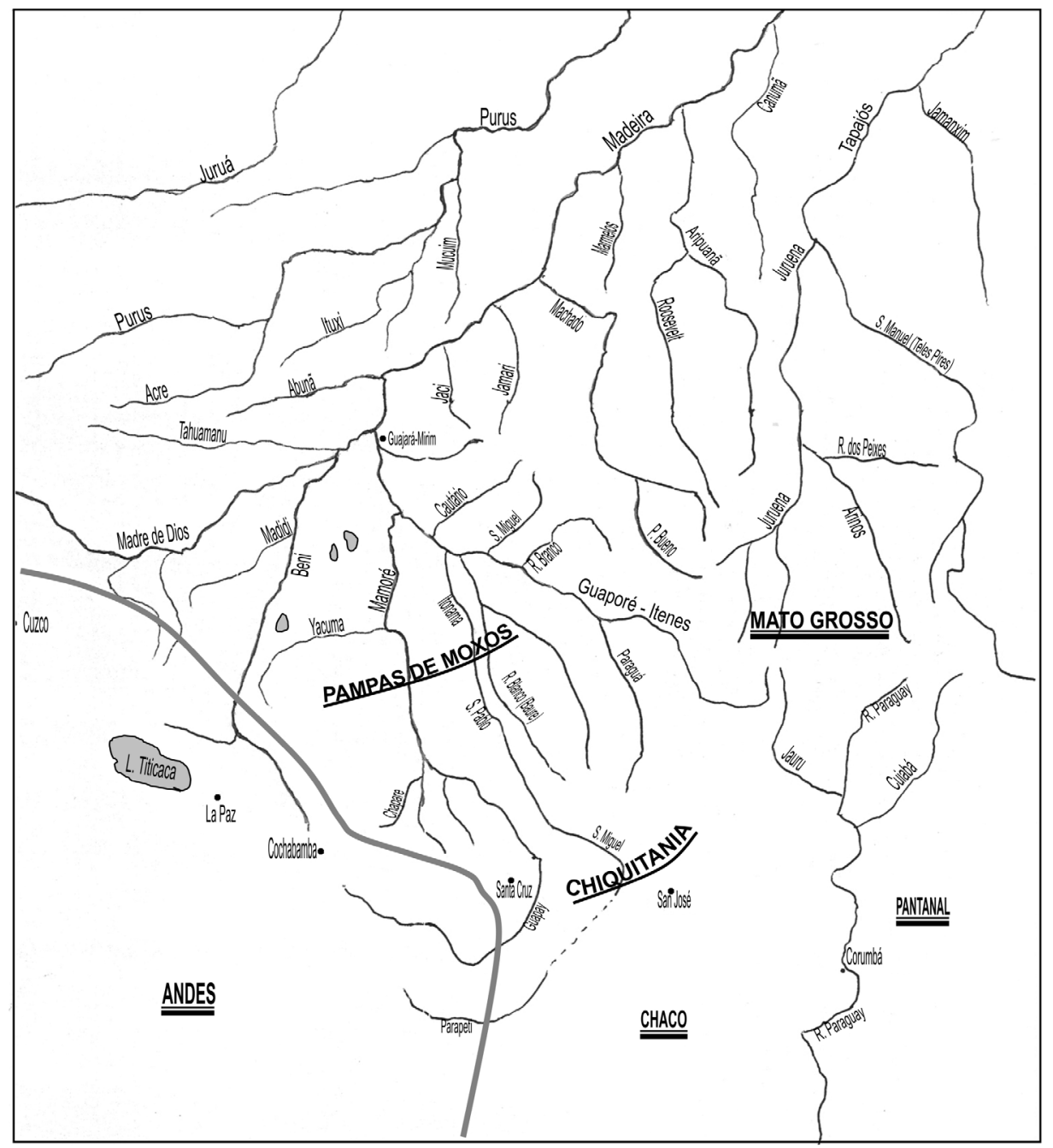

Figura 1 - O Grande Madeira 
colonizadores. Do lado espanhol, a ocupação das cabeceiras do Madeira ocorreu bem cedo. Em 1537, os conquistadores fundam Assunção no rio Paraguay e procuram ouro por todos os lados. Em 1561, Santa Cruz la Vieja é fundada por Ñuflo de Chávez, perto de S. José de Chiquitos, para ser transferida, nos anos 1600-1622, para sua posição atual no rio Piray. No século XVII, os franciscanos abrem as missões de Apolobamba com os povos takana, enquanto os jesuítas fundam duas províncias: uma nos Pampas de Moxos e outra em Chiquitos. Do lado português, o avanço efetua-se pelo rio Amazonas. O reconhecimento do Madeira até as primeiras cachoeiras data somente dos anos 1715-20, e o reconhecimento do Guaporé-Itenes começa apenas em 1740.

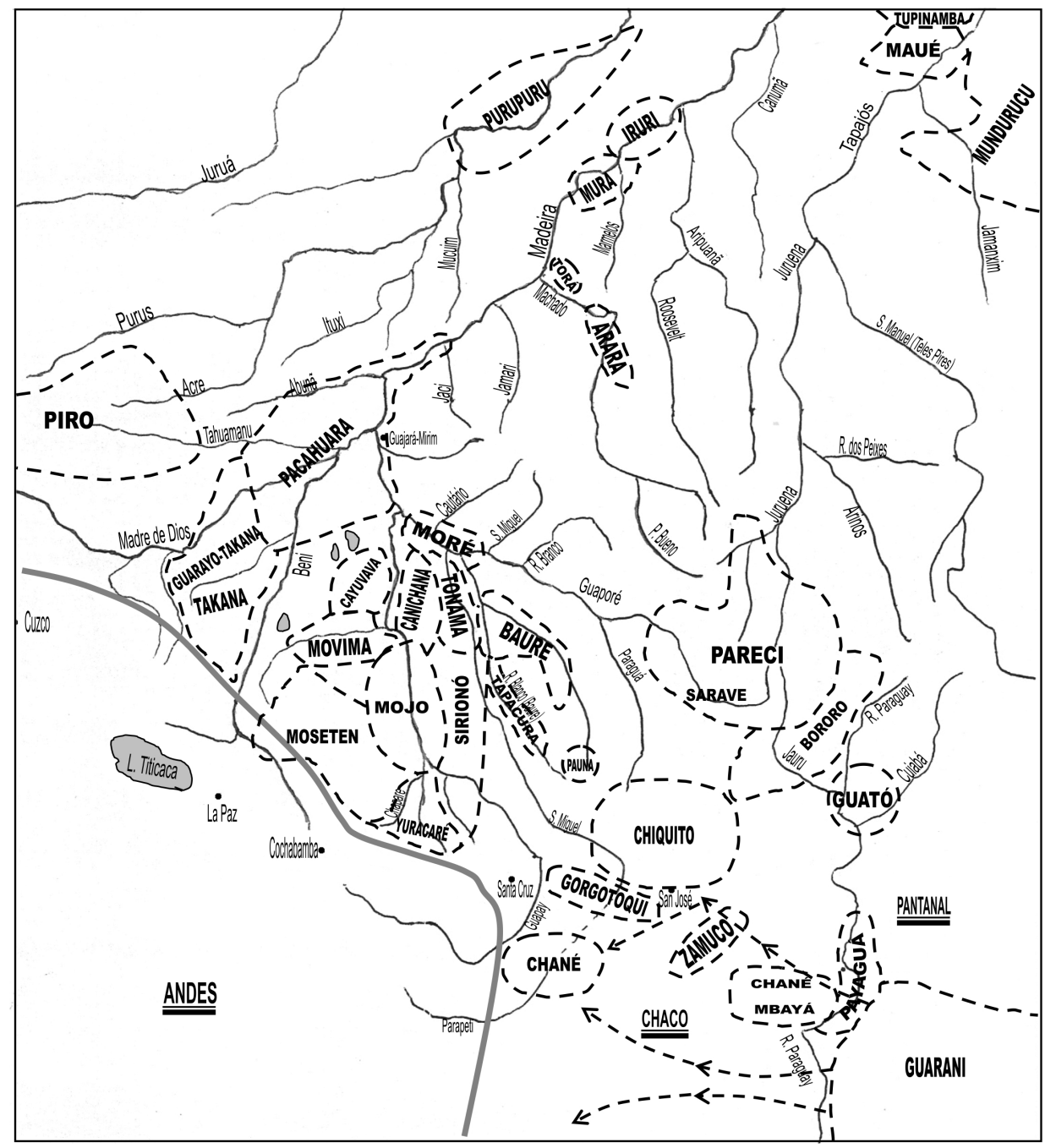

Figura 2 - Mapa étnico: 1521-1714 


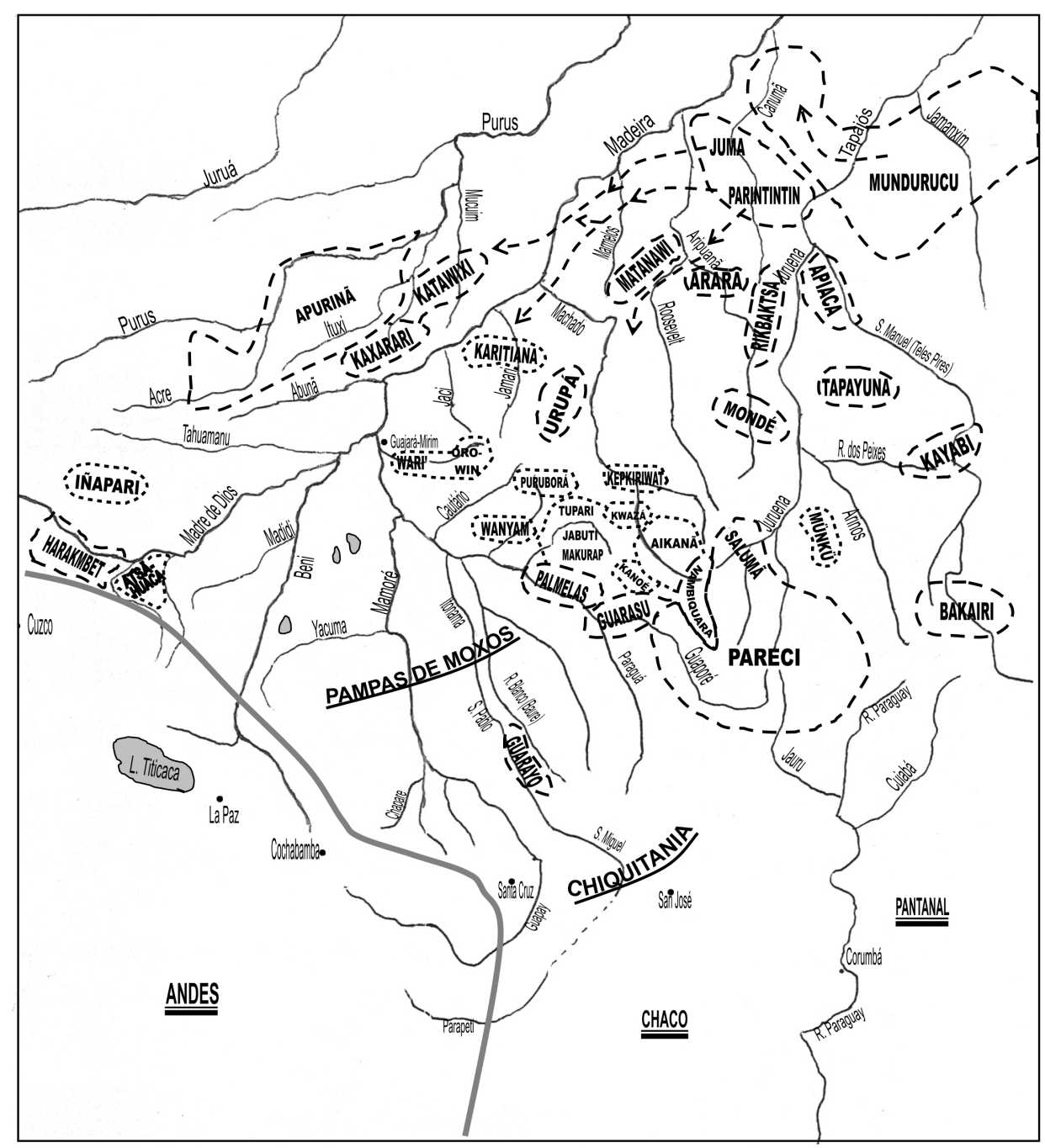

Figura 3 - Mapa dos grupos étnicos descobertos entre 1715 e 1935 (em pontilhado, os grupos descobertos no século XX)

Não é hora de fazer sínteses imprudentes, entretanto não podemos deixar de lado o que os mapas parecem sugerir:

1. A figura 2 poderia mostrar uma certa deslocação dos povos arawak da Bolívia: em primeiro lugar, há mais de 1.500 anos, uma intrusão dos Chiquito, vindos do leste ou do sul, separou os Pauna dos Chané, e foi seguida por uma invasão tupi-guarani mais recente, vinda do leste (Guarani, Guarayo), o que aniquilou ou assimilou certos grupos arawak como os Chané. 
2. A figura 2 mostra também a pressão exercida pelos Pacahuara (família pano) sobre vários grupos chapacura (Moré, Torá). O avanço desses grupos pano sobre o Mamoré pode ter sido provocado por uma expansão takana ou arawak vinda do sul e do oeste.

3. A figura 3 parece mostrar uma expansão dos Mundurucu, de certos grupos tupi-guarani (Juma, Parintintin, Apiacá, Kayabi), dos Arara do Aripuanã e dos Rikbaktsa para o sul ou o sudoeste. Esta expansão teria deslocado vários grupos tupi que se encontravam no caminho dos invasores para o atual estado de Rondônia. Isso explicaria a diversidade linguística que encontramos hoje entre o Machado e o Guaporé. Na falta de dados escritos, pensamos que um estudo pormenorizado dos empréstimos linguísticos e uma arqueologia focalizada nos séculos XVI-XIX, com excavações bem executadas e localizadas entre o Aripuanã e o Juruena, poderiam fornecer informações valiosas sobre o alcance dessas expansões e migrações.

\section{Métraux e os etnônimos Chapacura}

Do ponto de vista dos etnônimos, a monografia de Métraux sobre a família chapacura (1948:397-406) é bem mais clara que o artigo de Créqui-Montfort \& Rivet (1913a:119-171). Métraux pôde melhorar a realidade, acrescentando os Torá e os Urupá do lado brasileiro, grupos linguisticamente desconhecidos de Rivet por terem sido pesquisados apenas em 1925 por Nimuendajú. Métraux mostrou também que moré, muré e itene são etnônimos sinônimos, o que Créqui-Montfort \& Rivet (p. 122) não podiam ver por não disporem de fontes portuguesas. Esses autores não conseguiram situar corretamente as missões de Santa Rosa, San Miguel e San Simón, centros jesuíticos localizados exatamente à beira do Guaporé, entre o rio Cautário e o rio Branco, em 1749, antes de serem deslocados dentro da Bolívia por causa dos conflitos luso-espanhóis. A falta de documentação obrigou-os também a inserir povos chapacura em San Simón e em San Judas, sem suspeitar que essas duas missões eram na realidade uma só: a missão dos Santos Simão e Judas!

Contudo, Métraux repete o erro de Créqui-Montfort \& Rivet, declarando que os San Simonianos são provavelmente chapacura, equívoco pouco justificável em 1948, porque esses índios, instalados na Serranía de San Simón desde pelo menos a segunda metade do séc. XIX, já tinham sido visitados por Snethlage (1935:293). Este autor conseguiu um breve 
vocabulário que Loukotka (1968) analisou corretamente como pertencendo à família chiquitano. E também, mas sem que ninguém possa censurar, Métraux não conseguiu inserir os Wari' na família chapacura, por falta de dados linguísticos em sua época.

Com o correto restabelecimento dos etnônimos, Métraux (1948:398) mostra que apenas os Chapacura Próprios (Tapacura, Huachi, Guarayo) viviam na Bolívia: no médio e alto rio Blanco, um curso d'água que desemboca, junto com o San Martin, no Guaporé, abaixo da atual cidade de Costa Marques. No entanto, Maldi Meireles (1989) decide refazer uma síntese dos trabalhos de Créqui-Montfort \& Rivet, Nordenskiöld e Métraux sobre a família chapacura. No livro intitulado "Guardiões da Fronteira", paráfrase do vice-rey do Peru que - vendo o cinturão de missões jesuíticas que ia do Orinoco até o Paraguay e formava um bloqueio para o avanço português chegou a declarar, em 1646, que os habitantes das reduções indígenas eram "os custódios da fronteira" (Bayle 1951), Maldi Meireles escreve (1989:4546) (nossas observações entre colchetes):

Montfort e Rivet observaram notáveis pontos de identificação entre as línguas txapakura e as línguas aruak, a tal ponto de afirmarem uma inequívoca unidade de origem [a autora mostra assim que não leu Créqui-Montfort \& Rivet (1913:146) que depois de comparar as famílias txapakura e arawak - dizem: "não pensamos que se pode concluir por um parentesco, mesmo longínquo"!].

...É provável que os grupos txapacura tenham migrado, em tempos pré-colombianos, de regiões do alto Mamoré [i.e., no pé dos Andes bolivianos] por diferentes roteiros. Um deles teria seguido o curso do próprio Mamoré, que redundou na fixação de duas sociedades conhecidas como Herisobocono e Rokorono [os Rokorono eram um grupo moré do rio Guaporé, concentrado na missão de Santa Rosa, abaixo de Costa Marques, e deportado para o Mamoré depois dos ataques portugueses; os Herisobocono são também do Guaporé: cf. discussão detalhada na entrada Palmelas do glossário]. Outro, seguindo o rumo sudoeste, redundou na fixação dos antigos Tapacura no alto e médio rio Baures [errado: no rio Blanco].

...Os Moré podem ser remanescentes dos grupos que migraram ao longo do Mamoré e, possivelmente, devem ter sido expulsos pelos povos tupi [o contrário ocorreu: os Tapakura separaram-se de seus irmãos moré do Guaporé para invadir o rio Blanco e outras terras arawak da Bolívia. Isso é mostrado pelos empréstimos às línguas arawak da Bolívia (mojo, baure, 
pauna, tereno), que só se encontram em tapacura, e nunca em outras línguas da família chapacura. Como exemplos: makure abóbora [Mojo: makure, Baure: mokovise, Pauna: mukïe, Tereno: moko], mujek preá [Mojo: mujuku, Baure: mojoko, Tereno: mujuka-taka], po'e preguiça (animal) [Mojo/Baure: po'e, Pauna: upue], utxira capivara [Mojo: utxu, Baure: oxi, Pauna: ïtxï], mukure veado [Mojo: muka / muko, Baure: moka], kave cão [Baure: kove', Pauna: kave], turawawa caranguejo [Pauna: turawawa], meri banana [Pauna: merï], etc.].

...Muito remotamente - mas não antes do século XVII - alguns grupos txapakura atravessaram o Mamoré e se fixaram em alguns de seus afluentes da margem direita [i.e., no Brasil], onde estão, até hoje, os Pakaas-Novos [falso: os Pacanoa, Pacovas, Pacas ou Pacanagua da Bolívia, que moravam ao longo do Mamoré da foz do Abunã à foz do Guaporé, tendo sido missionados em Exaltación nos séculos XVII-XVIII, eram grupos pano bem conhecidos desde 1600. Esses Pakaas-Novos do século XVIII nada têm a ver com os Pacaás-Novos de hoje, que são os Wari', e portanto chapacura. Cf. discussão em 5.3. e na entrada Pacahuara do glossário].

...Os Pakaas-Novos, a única sociedade txapakura em território brasileiro [falso: até Métraux, que a autora copia palavra por palavra, cita grupos chapacura no Brasil, como os Torá e os Urupá]. ...Movimentos pós-colombianos conduziram ainda grupos txapakura do rio Baurés para o seu afluente San Simón, onde foram localizados os índios sansimonianos [falso: como já dissemos, os Sansimonianos pertencem à família chiquitano].

...Decididamente, o Guaporé agrupou secularmente os povos txapakura, não tendo sido observada a sua presença em nenhuma outra região [falso: os Torá e Urupá moravam no Madeira abaixo das cachoeiras].

Assim a pesquisadora vai pulando de equívoco em equívoco, seja por não entender Métraux, confundindo os Tapakura do rio Baure com toda a família txapakura, seja por confiar nas localizações propostas por CréquiMontfort \& Rivet, chegando - sem fundamento algum - a alegar uma origem meridional para toda a família chapacura.

Os dados linguísticos (Fig. 4; sobre o significado da cruz, cf. glossário em anexo) não nos autorizam tais digressões, porque sugerem que a família chapacura deve ser composta de duas subfamílias: a chapakura (com o reflexo u) e a chapakyra (com os reflexos y / i). A subfamília chapakura é formado por duas línguas muito próximas entre si: o torá e o moré-itene, com seus 
codialetos cautário e tapakura. A Figura 5 mostra como os Torá e os Moré poderiam ter sido separados, talvez por um fluxo de grupos pano, e como uma parte dos Moré - os Tapakura - migrou para o rio Blanco (Bolívia), o que parece comprovado pelos empréstimos arawak acima mencionados. Linguisticamente, tudo leva a crer - e nada mostra o contrário - que a origem da família chapacura deve ser procurada em áreas próximas ao baixo Mamoré, na fronteira boliviano-brasileira.

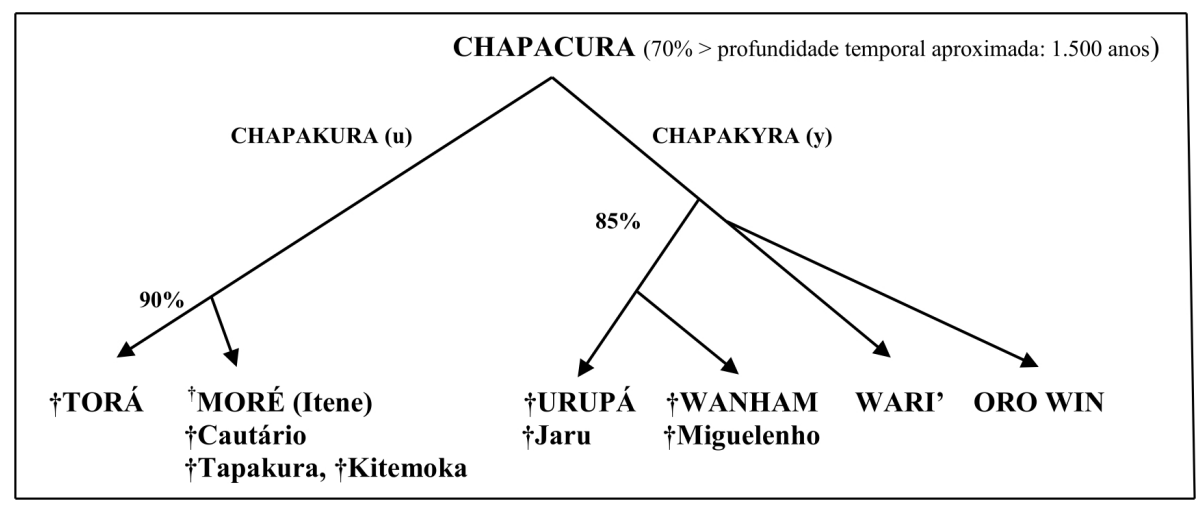

Figura 4 - A família chapacura

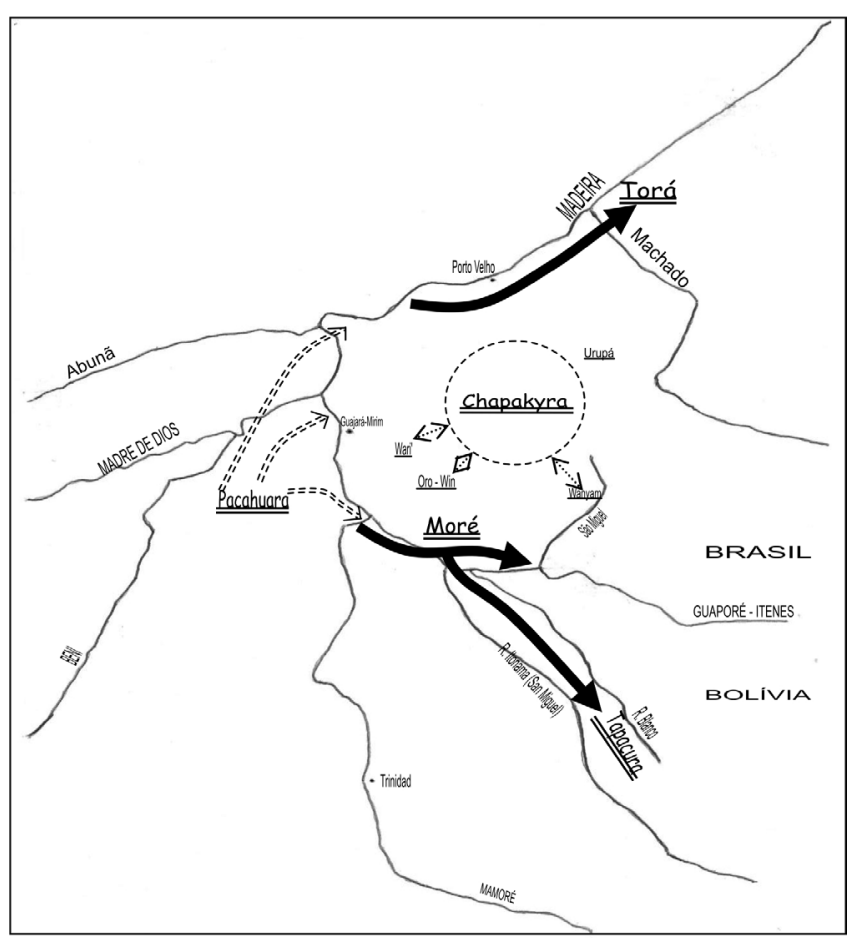

Figura 5 - Localizações e migrações chapacura 


\section{Métraux e os Guarayo}

De provável origem quíchua (< wara "tanga", -yuq / -yuh "portador de"), o wara-yuh é antes de tudo um etnônimo genérico e depreciativo, dado pelos moradores do império incaico a qualquer índio portador de tanga. Assim eram chamados os ferozes guarani provindos do Brasil e que, desde o fim do século XV, atravessavam o Chaco e subiam os Andes para saquear as fronteiras do Império Inca. Os caminhos de invasão parecem ter sido múltiplos. Também conhecidos como Cario, esses Guarani atravessavam o rio Paraguay, entre o rio Bermejo (ao sul de Assunção) e o Porto Itatim (no alto Paraguay, provavelmente no lago Mandioré), e cruzavam o Chaco. A mesma origem depreciativa deve ser encontrada nos etnônimos bolivianos sinônimos, como chiriwana, chiriguano, cherione e, talvez, sirionó. No decorrer do século XVI, o termo genérico guarayo estendeu-se a qualquer índio inimigo, selvagem, bárbaro, vindo do Brasil ou de qualquer outra parte do mundo, e que não aceitava a redução missionária e a "vida civilizada".

Até o século XIX, na Bolívia, o termo guarayo é genericamente aplicado aos Sirionó, aos Chapacura (Guarayo-Chapacura, Guarayo-Itene), a certas etnias das famílias chiquito, takana e pano, o que gerou uma tremenda confusão na interpretação deste etnônimo nos textos dos séculos XVI-XIX. No presente, o termo é somente reivindicado por um grupo tupi-guarani do departamento de Santa Cruz. Para Métraux, esses "Guarayo Próprios”, assim como os Guarasugwe (Guarayo Pauserna), teriam migrado do Paraguay no século XVI. Tal alegação será ulteriormente analisada.

Sobre os Guarayo, escutamos o que o padre Gregorio Bolívar, grande pioneiro franciscano, que viajou a pé de La Paz até o Madre de Dios em 1621 e conheceu muitos grupos tacana, disse (Bolívar 1906:181 e ss.):

Entre as ditas cordilheiras e o río Mano [rio Madre de Dios], seguem muitas províncias de gente bárbara, caribe e de má companhia e que são os Guarayos provindo do Brasil, que de grande parte do río Mano ocupam grandes regiões até o encontro com o río Diaben [rio Beni].

Esses Guarayo são os Esse-Ejja do Madre de Dios (família takana): até hoje vivem na fronteira com o Peru e, como os outros grupos takana, não têm nada a ver com o Brasil. Infelizmente, o padre Bolívar não é o único a se deixar enganar pela palavra guarayo. Em um trabalho confuso e superficial, intitulado "A área Madeira-Tapajós", em que um enorme branco aparece no mapa do interflúvio Madeira-Tapajós, Menendez (1998:293) mostra que 
também não sabe o que a palavra guarayo significa e que não entende os nomes dos rios dados pelos primeiros cronistas. Citando a carta do padre B. Rodrigues de 1714 (Leite 1938-43, vol. 3:393-394), que faz a lista das nações do Madeira:

Segue-se a das Cajaripunás, cuja multidão... Por último, habita uma e outra parte do Rio da Madeira a grandiosa nação dos Guarajus... Entra aqui o Rio Ipitiá, povoado todo da nação Arara, tão numerosa, que igualam as folhas do mato em que habitam...

Menendez (1998:295) comenta:

Os Guarajus voltam a ser mencionados como Guaraiutá por Gonçalves da Fonseca e são estudados por Riester, localizados nas margens do rio Itenes (Guaporé), sob a denominação de Guarasugwa.

Enquanto o padre Rodrigues se refere aos Guarayo-Takana do Madre de Dios, inimigos declarados dos Caripuna-Pano ou Cajaripunás, e enquanto o Madeira é para Rodrigues o Madre de Dios, Menendez pensa que se trata do Guaporé e dos Guarayo-Tupi. Vejamos em seguida comentários de Menendez sobre os Arara (p. 283):

Quanto aos Arara, Rodrigues os relaciona como numerosíssimos, ocupando a foz do rio Ipitia, provavelmente nome dado então ao Preto ou ao Machado [certo]... Fonseca faz referência, ao sul do Aripuanã, à ilha dos Arara, na região das cachoeiras do Madeira [não: aquela ilha fica perto da foz do Aripuanã e, portanto, não está situada - como ele supõe - nas cachoeiras acima de Porto Velho]... Essa série de localizações... sugere que os Arara iniciaram movimentos em direção sul [isso mostra que o autor confunde os "Arara-Pano das cachoeiras do Madeira", os "Arara do Machado" e os "Arara do Aripuanã”! ]

Mas voltemos agora à famosa alegação de Métraux. Para avaliar corretamente sua posição, precisamos conhecer profundamente a longa problemática guarayo. Tudo começa em 1822 com a chegada dos missionários franciscanos nas terras dos Guarayo Próprios, e logo depois, em 1832, com a viagem do famoso naturalista francês Alcide d'Orbigny. Para d'Orbigny, os povos da América do Sul podem ser classificados em três raças: a raça ando-peruana com 3 ramos (Quichua-Aymará, Yuracaré, Araucano), a raça pampeana também com 3 ramos (Pampeano, Chiquitano, Moxenho) 
e a raça brasilio-guarani com o único ramo guarani-botocudo. A partir do sul do Brasil, o ramo guarani costeou o litoral, marchando para o norte: suas hordas selvagens e guerreiras avançaram até as Antillas com o nome de Caribe (d'Orbigny já nota algumas semelhanças linguísticas tupi-carib) e remontaram o Orinoco e o Amazonas. Os Guarani do Paraguay seguiram o curso do Paraná e desceram até Buenos Aires, enquanto outros abandonaram em grande número o Paraguay em 1541, dirigindo-se para os Andes Bolivianos com o nome de Chiriguano. Hoje, tudo isso pode nos parecer extravagante ou linguisticamente ridículo, mas a influência de d'Orbigny na Bolívia era então enorme!

Por outro lado, d'Orbigny assinala corretamente que guarayo é sinônimo de itene, chapacura e chiquito. No entanto, há também outra tribo guarayo do ramo guarani em Santa Cruz. Segundo o naturalista, esses Guarayos propriamente ditos lembrariam terem chegado do sueste e terem sido amigos dos Chiriguano, com os quais acabaram brigando, acrescentando que, desde o século XVI, eles não mudaram de lugar de residência. Ele afirma que o guarani é a língua dos Guarayo, e que, desde doze séculos que os Guarayo abandonaram os outros Guarani, sua língua se modificou somente em detalhes de pronúncia. Na realidade, o guarani e o guarayo são dois dialetos bem mais diferentes do que d'Orbigny insinua. Em resumo, com seu famoso ramo guarani, o centro de dispersão dos Guarayo só poderia ser o mesmo dos Guarani, dos Botocudo e dos Carib: o Paraguay ou o sul do Brasil.

No entanto, certos missionários franciscanos estão longe de concordar com isso. Para o padre Vuidez, a origem dos Guarayo estaria ao nordeste - e não ao sueste - da Chiquitania, sua tradição oral indicando a junção de dois rios perto dos seus inimigos chiquitano, além do morro Guarayus, que fica entre Vila Bela e Santa Ana (Cardús 1886:65-66). No fio desta intricada discussão, veremos que isso é o mais provável, mas o padre Cardús, cronista franciscano, critica logo esta nova alegação (Cardús 1886:67):

Parece-me que a simples denominação ou o nome de uma tribo imposto a um lugar não é uma razão suficiente para deduzir que dita tribo tenha tido ali sua residência, principalmente tratando-se dos Guarayos. Do contrário, deveríamos também dizer que os Guarayos têm vivido sobre o rio Itenes, porque ali, perto de Las Pedras [Pedras Negras], há um lugar que se chama Guarayus; poderíamos dizer que os Guarayos têm tido sua residência entre Concepción e San Miguel de Chiquitos, porque em dito trecho existe um lugar que se chama Guayarito; também poderíamos dizer que os Guarayos têm vivido ao sul de 
Chiquitos, porque na mata grande, entre Santa Cruz e El Cerrito, há dois campos denominados, um de Guayaritos, e outro de Guarayos; igualmente poderíamos dizer que os Guarayos têm estado sobre o rio Beni, porque ali também há um lugar que se chama Peña de Guarayo. E, no entanto, ninguém até agora pensou que os Guarayos propriamente ditos tenham estado em lugares tão distintos, tão distantes e tão opostos entre si. Não parece certo, pois, nem tampouco provável, que os Guarayos tenham sido encontrados ao nordeste de Chiquitos [entre Santa Ana e Vila Bela], nem que desde ali tenham sido transladados a San Javier, para ocupar depois os lugares imediatos aos que atualmente ocupam...

e acaba concluindo que prefere seguir a teoria de d'Orbigny por razões linguísticas e históricas, porque as migrações dos Chiriguano teriam começado no Paraguai!

Examinemos agora a posição de Métraux (1948:430-431):

Os Guarayú e os Pauserna formavam uma só tribo, mas separaram-se quando os ancestrais dos Guarayú modernos foram recolhidos em missões. Os Pauserna são os descendentes dos Guarayú que ficaram independentes... Os Guarayú vivem entre o rio San Miguel e o rio Blanco... Os Pauserna (Guayaruta) vivem no alto Guaporé, onde o pau cerne é abundante; daí seu nome [o pau cerne é uma espécie silvestre que os botânicos nunca descobriram e que, até hoje, só foi mencionada por Métraux!]... Antigamente, eles atingiam o baixo Rio Paraguay [erro tipográfico lastimável, pois trata-se do rio Paraguá, afluente do Guaporé que nasce na Chiquitania, e não do rio Paraguay]... Os Guarayú, como os Chiriguano, são descendentes dos Guaraní do Paraguay que, no fim do século XV e no começo do século XVI, atravessaram o Chaco e a Província de Chiquitos em pequenos grupos para atacar as fronteiras do império Inca... Os primeiros documentos usam frequentemente o nome guarayú para todos os índios guaraní (Chiriguano e Guarayú propriamente dito), que tinham migrado do Paraguay... Em 1695, o padre Cipriano Barrace manteve contato com eles... A missão de Juan Bautista de Guarayos foi fundada para os Guarayú.

Entretanto, a posição de Métraux é equivocada. No guarayo propriamente dito há uma influência das línguas arawak da Bolívia (pauna, mojeño, baure), em palavras como kawé "cão", u'o "macaco zogue-zogue", merï / apu "banana", etc., o que não se verifica no guarayo do Paucerne (ou guarasugwe). De fato, 
o guarayo propriamente dito e o pauserna (ou guarasugwe) são fonologica e lexicalmente tão distintos que é altamente improvável que eles teriam sido "uma só tribo", que se teria dividido depois do século XVI. Como poderiam ter sido "uma só tribo" se todos tivessem vindo do Paraguay e se os Guarasugwe tivessem passado por terras arawak sem sofrer, como os Guarayo propriamente ditos sua influência? Riester(1977:31) tem a mesma opinião, porque as diferenças culturais são demasiadamente significativas entre os Guarayo propriamente ditos e os Guarasugwe; e Miller (1983), também, após investigações arqueológicas na área pauserna, duvida da alegação de Métraux.

Este esquema Métraux tem em mente desde 1927, mas por outras razões que não as de d'Orbigny. Com efeito, ele sabe que a origem dos povos tupi não seria mais o Paraguay de d'Orbigny, mas "o alto Tapajós ou o Ji-Paraná" (Métraux 1928:310), porque as expedições de Rondon haviam acabado de descobrir um grande número de povos tupi nesta região. Portanto, Métraux precisa agora de provas históricas. Resumindo o assunto, eis tudo o que se pode realmente encontrar nos arquivos (Gandia 1935:92):

[1564] Em Assunção Ñuflo de Chávez organizou a expedição de Ortiz de Vergara, que [com] 120 espanhóis e 30 mestiços, todos embarcados em 21 navios aos quais seguiam 80 canoas de índios amigos, partiu de Assunção em outubro do ano 1564. Por terra formavam parte da expedição outros 30 espanhóis com 800 cavalos. Na viagem até o Porto Itatim [no alto Paraguay, acima da atual Corumbá], os expedicionários perderam 80 cavalos. Ortiz de Vergara desfez 12 navios e os restantes os enviou a Assunção com um capitão e 30 homens. Desde o Porto Itatim, Ortiz de Vergara empreendeu a travessia do Chaco, aumentada sua expedição com uns 3.000 índios itatines [ou melhor: cario] que logo se estabeleceram a umas trinta léguas $[150 \mathrm{~km}$ ] de Santa Cruz da Serra [Santa Cruz la Vieja, a $12 \mathrm{~km}$ ao sul de San José, cf. Fig. 2], junto com outros índios de sua mesma raça que os haviam precedido (em 1513-18, cf. Maurtua, V 1906, vol. 6) dando origem às tribos chamadas guarayu.

Para tentar elucidar o problema, examinaremos o excelente dicionário étnico de Combès (2010), que analisa mais de 600 etnônimos repertoriados pelos espanhóis entre 1542 e 1600, a $150 \mathrm{~km}$ ao redor de Santa Cruz la Vieja. Esses etnônimos são de interpretação linguística tão delicada que o próprio Métraux confessava encontrar-se diante de uma das situações mais "desesperantes" da etnologia sul-americana! 
No século XVI, encontravam-se dois principais blocos de língua guarani na Bolívia:

$1^{\circ}$ ) os "Chiriguanaes de la Cordillera", estabelecidos ao sul da atual cidade de Santa Cruz, povoando o pé dos Andes até o sul do rio Pilcomayo;

$2^{\circ}$ ) os "Chiriguanaes de Itatín", "Guarani itatines" ou "Guarayu", que viviam ao nordeste de San José, entre os povos chiquito e bororo; neste bloco, devemos incluir os grupos de Pitaguari e de Bambuguasu.

Os jesuítas que chegaram em Santa Cruz em 1585 estudaram as línguas faladas na periferia desta cidade (chané, chiriguano, gorgotoqui) e não mencionaram diferenças linguísticas ou culturais entre os dois blocos chiriguano-guarani. Nota-se também que, ao contrário dos Chiriguano da Cordilheira, os Chiriguano de Itatim tornaram-se logo amigos dos espanhóis e dos padres que os batizavam.

A visão bipolar que apresentamos foi intencionalmente simplificada: havia também os Guarani das Montanhas (perto do Jauru) e outros grupos chiriguano ao oeste e ao norte da Chiquitania, perto do Guaporé. Estes últimos sim poderiam ser os ancestrais dos Guarayo.

Quanto ao Porto Itatim no rio Paraguay, era povoado por Guarani ou Cario, e não por Itatines. Portanto, a citação de Gandia deve ser lida da forma seguinte: em 1564, 3.000 Cario saíram do Porto Itatim e foram engrossar os bandos chiriguano de Pitaguari, que viviam ao nordeste de San José. Adotando o nome de sua origem no rio Paraguay, formaram assim uma "Província de Itatim" em plena Bolívia.

Havia outra Província de Itatim na mesma época, mas desta vez a leste do rio Paraguay:

[Irala, em 1538]... foi à província de Ytati, e subjugou os índios de Atirá, Guarambaré e Ypané ou Pitum. Todos os citados índios são guarani (Azara 1962:452).

Esta província oriental começava no rio Jejuy, um pouco ao norte de Assunção, e devia estender-se ao norte até o rio Miranda. Os Guarani desta segunda Província de Itatim foram posteriormente missionados pelos jesuítas do Paraguay (1631-1669) e, depois da desintegração das reduções, migraram para o sul, no rio Ipané, onde viviam seus "parentes" guarambaré. Os descendentes desses Guarani poderiam ser, pelo menos em parte, os modernos kaigwá. 
Em resumo, "tribos chamadas guarayu" significaria simplesmente "tribos que se tornaram selvagens e hostis", e os arquivos não demostram absolutamente nada quanto à identidade linguística dessas tribos. Métraux sabe muito bem que todo índio bravo era chamado "guarayo" na Bolívia, e ele diz justamente, na citação acima referida, que:

os primeiros documentos usam frequentemente o nome guarayú para todos os índios guaraní que tinham migrado do Paraguay,

Certos grupos chiriguano e tapieté do rio Parapetí, que foram viver no Paraguay depois da guerra do Chaco (1935), ainda são conhecidos como guarayu.

Então, por que não testar o resto da citação, tentando descobrir realmente o que se esconde aqui atrás da palavra "guarayo"?:

em 1695, o padre Cipriano Barrace manteve contato com os Guarayú... A missão de Juan Bautista de Guarayos foi fundada para os Guarayú.

Neste caso, podemos mostrar que Métraux está equivocado e que a citação dele não fala de Guarayo propriamente ditos, mas de Sirionó. Por isso, recopiamos do glossário em anexo a posição exata dos Guarayo e dos Sirionó no século XVIII (cf. também Fig. 2 e 3):

Guarayo [1793, Cardús (1886:88)]. Família tupi. Ao norte de San Javier (Chiquitania): entre o rio San Pablo (San Miguel) e o rio Blanco.

Sirionó [1675, Castillo (1906:295-276)]. Família tupi. Outros nomes e grupos: Mbya, Yuqui, Chori, Jorá, †Guarayo. Faixa única e uniforme do rio Yapacani (no sul) ao rio San Pablo ("Monte Grande de San Pablo") até El Carmen e o Lago San Luis ao norte. Como nota justamente Cardús (1886:280): "Não obstante a grande extensão de terreno que ocupam, os Sirionos não são tão numerosos, como parece que deveriam e poderiam ser. Como não cultivam a terra, e como todos vivem somente de caça, pesca e frutas silvestres, por necessidade têm que viver en frações pequenas, apartados uns dos outros, e mudar com frequência de lugar; e esta é a razão por que, sem ser tão numerosos, vê-se esses índios em tantos e tão distintos pontos". A primeira menção encontra-se em 1675 em Castillo (1906:295) que situa os Sirionó no rio Yapacani (a oeste de Santa Cruz) com a denominação de Guarayo (são os atuais Yuqui). Mesma confusão com o padre Barace que, atravessando o Monte 
Grande de San Pablo ("Mata de San Pablo"), de Loreto a Baure em 1693, encontra índios que ele chama uma vez de Sirionó (Lettres édifiantes et curieuses, 1780-83, vol. 8:105) e outra vez de Guarayo (Chávez Suárez 1986:236-237). Na realidade, não se trata de confusão: enquanto o etnônimo sirionó é específico, o termo guarayo é genérico, usado para qualquer índio inimigo.

Como Cardús (1886:69) nota finamente:

Os Sirionos e Guarayos ocupam seus respetivos lugares desde há quatro séculos. Somente assim se pode entender que o P. Baraza, conforme ele mesmo disse, em 1693, e a leste de Loreto, em Mojos, pudesse ter encontrado 66 povoados (casas) de Guarayos, supondo que os Guarayos de quem fala tivessem sido verdadeiramente tais.

Assim, o padre Barace, que andava no Monte de San Pablo, nos Pampas da Província de Mojos, encontrou necessariamente os Sirionó e não os Guarayo, que vivem em outra parte da Bolívia. Basta entender que os Sirionó viviam na Província jesuítica de Mojos e os Guarayo, ao norte imediato da Província jesuítica de Chiquitos. A missão de San Juan Bautista de Guarayos, a que se refere Métraux, fundada em 1710 e abandonada em 1718, pertencia à Província de Mojos, em pleno território sirionó, nos limites de Trinidad e de Loreto (cf. localização em Chávez Suárez 1986:266267) ${ }^{3}$. Então, que devemos pensar da interpretação dos textos do século XVI se Métraux não consegue interpretar quem são os Guarayo nos textos dos séculos XVII e XVIII? Como se pode concluir o passado dos Guarayo e dos Guarasugwe (Pauserna) e sua origem ao sueste ou nordeste da Chiquitania permanecem uma incógnita nos arquivos.

No entanto, Maldi Meireles (1989:40-43) decide refazer uma síntese dos trabalhos de Métraux, copiando o texto em ordem diferente e acrescentando algumas palavras para tornar as asserções de Métraux ainda mais tumultuadas:

Os Guarayo e os Pauserna formavam uma única sociedade... Quando foram recolhidos às missões no século XVII [as missões franciscanas guarayo são do século XIX], parte do grupo se manteve independente e se estabeleceu nas margens do rio Paraguá, afluente do Guaporé, onde o "pau cerne" era abundante

\footnotetext{
${ }^{3}$ Não excluímos a possibilidade desses Guarayo da missão de San Juan Bautista serem um grupo chapacura, mas isso é pouco provável: a primeira missão oficial com os Tapacura, Nuestra Señora del Carmen de Guarayos, foi aberta em 1794, a 12 léguas ao sul de El Carmen, no rio Blanco (Chávez Suárez 1986:439-441).
} 
[mais alguém que conhece o misterioso "pau cerne"!]. No século XIX, migraram para perto do Rio Verde, aproximando-se mais do Guaporé [de 1750 até hoje, os Pauserna estão exatamente na beira do Guaporé, abaixo de Pimenteiras! No seu mapa, a autora colocou erradamente o igarapé Paucerne do lado brasileiro: será que existem dois rios Paucerne?].

...Grande parte da população guarayo foi recolhida às missões de Chiquitos [Métraux (1948:431) diz somente: "alguns Guarayú", o que é muito mais provável]. Em 1695, Frei Cipriano Barrace levou alguns para a missão de San Javier [San Javier de Mojos? San Javier de Chiquitos? A segunda opção, que a autora parece sugerir, é impossível: o padre Barrace andava na Província de Mojos] e, posteriormente, foi fundada a missão de San Juan Baptista de Guarayos [na página 94, a autora confessa não conseguir localizar esta missão no seu quadro das missões de Chiquitos. ${ }^{4}$ Claro: a missão de San Juan Batista de Guarayos ficava nos pampas de Mojos, e não na Chiquitania].

No trabalho de Maldi Meireles, há muitos erros. Ela começa por se confundir com os números (1989:31-34):

No final do século XVIII, a população mojo atingia cerca de 40.000 pessoas distribuídas em 72 aldeias, cada uma com uma população média de 60 a 80 habitantes $[72 \times 70=5.040$, e não 40.000]... em 1700 os Baure totalizavam 80.000 pessoas distribuídas em 124 aldeias [isso está mal copiado, os jesuítas mencionando 40.000 baure em 65 aldeias para essa data, mas - como d'Orbigny e Cardús (1886:69) já tinham ironicamente notado - os jesuítas confundiam aldeias e casas: a população baure não teria passado de 15.000 pessoas em 20 povoados].

Na segunda parte desse trabalho (1989:127) e em outro escrito(1983:2426), ela cita erroneamente Hugo e Miller para declarar que os Amniapä, os Guaratagaja, os Cabixiana, os Palmela e os Huari viviam no Vale do Guaporé nos anos 1750: os Palmela foram mencionados somente na segunda parte do século XIX (por Fonseca em 1875) e os outros etnônimos, no século XX, por Snethlage e Nordenskiöld. Essa confusão distrai o leitor sobre os problemas das fontes que foram ou ignoradas ou - no caso de Métraux e de Créqui-Montfort \& Rivet - consideradas como sagradas.

\footnotetext{
${ }^{4}$ Não entendemos porque a autora não consegue localizar a missão de San Juan de Chiquitos. Desde o século XVIII, todos os mapas coloniais colocavam corretamente San Juan a $40 \mathrm{~km}$ a leste de San José, no lugar conhecido hoje por Taperas. Os grupos aldeados naquela missão eram chiquito e zamuco, e não guarayo, como a autora escreve na sua precária compilação.
} 
Outros trabalhos não recomendados para o etno-historiador e o linguista:

- o trabalho de Cabral (1963), por adulterar as fontes e transformar assim seu livro em verdadeiro romance;

- e os três volumes de Montaño Aragón (1987-92), no qual o autor inventa ou altera vocabulários de leco, aguachile, apolista, capillo, etc., criando também novas famílias linguísticas, como a família linguística chunene, sem ver que o vocabulário que ele apresenta é esse-ejja (família takana), e a família paiconeca, sem ver que se trata de um simples dialeto baure (família arawak).

\section{Outros equívocos}

\subsection{Parintintin, Juma, Kawahib e Cinta Larga. Etnônimos genêricos, as palavras parintintin e kawahib(a) [< Tupi-Guarani: kab vespa?] "índio bravo, hostil" deram lugar a muitos equívocos}

Para Nimuendajú $(1924,1948)$ e para Lévi-Strauss (1948:299-300), os Kawahib, depois de ter sido destroçados pelos Munduruku no começo do século XIX, teriam fugido da confluência Arinos-Juruena (alto Tapajós) para o rio Branco (afluente do rio Roosevelt) e de lá se teriam espalhado no rio Machado, no rio Marmelos e outros afluentes do rio Madeira.

Nimuendajú (1924:50-53) argumenta que os Parintintin e os Tupi do Machado são os fragmentos da antiga tribo cabahybas (kawahib) do Alto Tapajós, mencionada no fim do século XVIII, mas que, mais tarde, desaparece daquela região. Verificamos todas as referências de Nimuendajú, reconhecendo que sempre foram fielmente reproduzidas:

1) os Kawahib no vale do Tapajós: em 1797, os Cabahibas - de Língua Geral (tupi-guarani) - vivem próximos da confluência do Arinos com o Juruena, abaixo dos Apiacás. No começo do séc. XIX, Castelnau os situa a oeste do Juruena, afastados deste rio pela hostilidade dos Apiacás. Em 1817, Ayres de Cazal diz também que os Cabahybas vivem ao norte dos Apiacás e que falam a mesma língua. No entanto, em 1819, há Cauahipe no rio do Sangue. Note que Nimuendajú (1948:283) menciona também os Cawahib entre o Arinos e o Juruena em 1844. Diferentemente dessas fontes, em 1820, Martius situa os Cabahybas no rio São Manuel (Teles Pires), onde se encontram os atuais Kayabi (ao norte de Sinop). Depois, conforme Nimuendajú, o etnônimo Kawahib desaparece. 
2) o etnônimo parintintin aparece em 1817 com Ayres de Casal como índios que dilatavam muito as orelhas com rodelas, o que se parece muito com os Rikbaktsa e pouco com os Parintintin! Em 1780-1790, os Juma - que tinham receio dos Mundurucu - costumavam atacar a cidade de Borba perto da qual eles viviam (Castelnau 1850, tomo 3:124). Em 1820, os Juma e os Parintintin são mencionados nos altos cursos dos rios Canumã e Maués, entre o Madeira e o Tapajós (Spix \& Martius 1981:276), com tatuagem no rosto e nos antebraços, o que lembra muito com os atuais Parintintin. Da mesma época ou um pouco antes, os Parintintin são mencionados ao oeste e ao norte da Cachoeira de Todos os Santos (no rio Juruena, $8^{\circ}$ lat. S.), tocando o território dos Mundurucu na foz do rio Cururu (Castelnau 1851, vol. 3:104). A partir de 1829, os Parintintin antropófagos são citados no rio Madeira (Castelnau 1851, vol. 5:164). Entre 1852 e 1923, numerosas e sangrentas lutas são citadas entre Parintintin e "civilizados" na área do rio Marmelos. Em 1875, os Parintintin são mencionados no rio Urupiara (perto do rio Marmelos) e no rio Jamari (Rondônia) por Souza (1875:132-133). Em 1889, os Juma fazem sua aparição entre o rio Mucuim e o rio Ituxi, no interflúvio Madeira-Purus (Labre 1889:501).

O outro artigo de Nimuendajú (1948:283-285) repete os mesmos argumentos, mas não apresenta mais os dados de Martius. Sem querer fazer um processo de intenção ao autor, devemos alertar o leitor que a omissão desses dados é extremamente grave porque Martius justamente proporcionava dados que resolviam este quebra-cabeça, abrindo o caminho para mostrar que os Parintintin e os Kawahib deviam ser tribos diferentes.

De fato, o etnônimo kawahib - na confluência Arinos-Juruena - aparece no século XVIII, mas - contrariamente ao que afirma Nimuendajú - continua na mesma confluência até o século XX para designar os Tupi-Mondé, e não os Parintintin, como Nimuendajú o supunha! Com efeito, em 1962, os Cinta Larga do Juina-Mirim (perto da atual cidade de Juina e daquela confluência) são chamados de Kawahib pelo S.P.I. e pelos jesuítas, ou de Kawahyb pelos índios kayabi do rio dos Peixes (Gama Malcher 1964:101-113).

O leitor habituado aos textos coloniais sabe o que valem as menções do tipo "Língua Geral" ou "mesma língua". O fato que os Cabahibas de Almeida e Serra, índios que ele nunca viu pessoalmente, teriam falado a Língua Geral tem o mesmo valor que, por exemplo, as asserções do padre Bettendorf, excelente conhecedor de tupi-guarani, quando declara que os 
Juruna do Xingu são índios de Língua Geral (Bettendorf 1910:115), o que está totalmente errado!

Isso indica que os dados recolhidos no começo do século XIX por Martius e por Castelnau parecem certíssimos: os Parintintin e os Juma de Martius são os Parintintin e os Juma de hoje, a conjunção de dois nomes idênticos não podendo ser aleatória! Eram índios do interflúvio MadeiraTapajós que viviam atrás de Borba, entre o alto Canumã, o Baixo Aripuanã e as fontes do rio Maués. Infelizmente, Nimuendajú desapareceu antes de saber da existência dos Kawahib-Mondé e sem poder fazer a conexão linguística (mesma língua tupi-guarani) entre os Juma do Mucuim, que então eram isolados, e os Parintintin!

Em outras palavras, os Parintintin e os Juma, depois de terem sido destroçados pelos Munduruku no fim do século XVIII e no começo do século XIX, expandiram-se no rumo sul pelo Madeira e pelo Aripuanã-Roosevelt até o século XX, enquanto que os Kawahib, provavelmente os Mondé (Suruí e Cinta Larga), afastaram-se lentamente da confluência Arinos-Juruena (alto Tapajós), desalojados de lá pelos Apiaká e, depois, pelos Rikbaktsa. Por outro lado, como etnônimo genérico, Kawahib não se referiu sempre aos Mondé: os Cabahybas de Martius (1820), acima mencionados no São Manuel, poderiam ser os Kayabi.

Como Kawahib, os Mondé do Juruena poderiam assim marcar a sua presença no Juruena há séculos. Em 1727, na área acima referida do Juruena, os terríveis índios antropófagos Cavihi foram descritos usando potes em que eles cozinhavam tripas humanas (Campos 1862:445-446). Esses Cavihi bem poderiam ser os Cabahiba mencionados em 1797 no mesmo lugar. Tudo isso sugere que, no começo do século XVIII, os Mondé viviam entre os Pareci e os Rikbaktsa, perto do rio do Sangue, como a tradição oral suruí parece confirmar.

\subsection{Nambiquara, Rikbaktsa e Tapanhuna}

O pequeno artigo de Price sobre os etnônimos cabixi e nambiquara (1983:129-148) merece toda nossa atenção pelo rigor de suas referências bibliográficas, pois, desde as monografias de Métraux, Lévi-Strauss e Nimuendajú, é o melhor trabalho de etno-história na área. Infelizmente também, é um dos únicos de que dispomos. O leitor é convidado a seguir a gênese do etnônimo cabixi, aplicado do século XVIII até hoje a certos grupos pareci, mas que se estendeu, durante o século XIX e o começo do século 
$\mathrm{XX}$, a vários grupos agressivos das famílias nambiquara ou chapacura. Price (1983:138) mostra também de forma convincente que os Nambiquara de Rondon são os Tamaré do século XVIII. No entanto, Price (1983:141-142) termina seu trabalho copiando Lévi-Strauss (1948:361), que salientou o erro de Rondon quando este batizou de "Nambiquara" o povo da Chapada dos Parecis "que dorme no chão", povo que ele acabava de descobrir:

Nambicuara, que significa "orelha comprida", era um apelido dado no século XVIII a tribos como os Suya que eram chamadas de "Beiços de Pau". Nos anos de 1830, essas tribos começaram a se mostrar hostis. Quando, em 1907, o General Rondon descobriu importantes tribos na Serra do Norte, ele as identificou aos Nambiquara do passado. Portanto, Nambiquara designa outra tribo que a das "orelhas compridas" à qual o termo era aplicado na origem.

Com isso, Price reforça o que Lévi-Strauss acertadamente afirmara: Rondon tinha dado um nome errado à tribo que acabava de descobrir, os seus "Nambiquara" tendo pouco a mostrar nas orelhas. No entanto, pensamos que Price e Lévi-Strauss erraram quando afirmaram que os Nambiquara dos séculos XVIII e XIX eram os Suyá (Tapayuna, Beiço-de-pau). Os textos de 18451848 (Castelnau 1851, vol. 2:307, Steinen 1894:549-552) sempre separam os Tapanhunas dos Nambiquaras ou Nhambiquaras. Ao nosso ver, os Nambiquara do passado só podem ser os atuais Rikbaktsa. As fotografias rikbaktsa tiradas por volta de 1960 (Gama Malcher 1964:101-113), com enormes bodoques nas orelhas, e as referências escritas ou orais dos ataques dos Rikbaktsa contra os Apiaká (1830), os Münkü (1920) e os Cinta-larga (1900) não deixam lugar a dúvida alguma. Em 1915, os Rikbaktsa, inimigos dos Münkü, aparecem no baixo rio do Sangue com o nome de Nambiquara (Rondon 1916). E o padre Adalberto Holanda Pereira (que Price citou em comunicação pessoal!) pode escrever corretamente, onze anos depois de Price:

Tudo nos leva quase a crer que [os índios nambiquara de Steinen (1872)] são os índios rikbaktsa ou canoeiro de Mato Grosso, já que esses índios têm o lóbulo furado e distendido, para uso do bodoque, que chega a ter seus $20 \mathrm{~cm}$ de diâmetro (Holanda Pereira 1994:11)

\subsection{Caripuna e Pacaas-Novo}

Depois da publicação do HSAI, os equívocos sobre os etnônimos brasileiros atingiram o seu paroxismo: os Caripuna (pano), os Pacaas-Novo 
(pano) e os Mequéns do século XVIII tornaram-se tupi ou chapacura durante o século XX.

Sobre os Pacahuara ou Caripuna (família pano), lemos nos séculos XVIII e XIX:

Os Pacaguaras estão espalhados em uma grande extensão de terreno, mas divididos em pequenas facções, com diferentes nomes, como Chacobos, Sinabos, Capuibos, Caripunas, etc. (Cardús 1886:291).

Esta nação, conhecida dos espanhóis das missões de Moxos e dos indígenas com o nome de Pacaguara, é denominada com uma palavra distinta pelos brasileiros [Caripuna]. Os Pacaguara, que têm sempre habitado a confluência dos rios Beni e Mamoré, mantêm relações com os Cayuvavas. Muitas vezes foram levados a Exaltación [no rio Mamoré] para convertê-los ao cristianismo (d’Orbigny [1832]1944:362).

[na Cachoeira do Jirau, acima de Porto Velho] habita a nação caripuna... a cartilagem que divide o nariz tão bem furada, e por este furo atravessam um tubo da cor de âmbar, de três polegadas de comprido e quatro linhas de grosso; alguns têm umas curtas barbas e bigodes, e do meio delas lhes pendem uns semelhantes tubos porém mais grossos e compridos... Eu me animo a dizer que esse gentio deve ser tratado com toda a brandura pois pela sua desconfiança, robustez e ferocidade, pode vir a ser uma vez escandalizado, um perigoso inimigo, muito mais funesto, pela sua situação [trecho encachoeirado do Madeira], do que o gentio Mura (Almeida e Serra [1790]1857:16).

Assim, Caripuna ou Cayaripuna era o nome que os portugueses davam aos Pacahuara dos espanhóis. Esses Pacahuara formavam um conjunto de clãs ou grupos pano de língua idêntica (cf. entrada Pacahuara no glossário em anexo), e facilmente reconhecidos pelo longo tubo que furava o septo nasal, por típicas canoas de casca e por um poncho ou capa quadrangular, com uma abertura pela qual se passava a cabeça, uso este que possivelmente tinham adquirido na missão jesuítica de Exaltación.

Sobre os Caripuna / Cayaripuna (pano) perto de Guajará-Mirim, cf. comentários de Palheta em 1723 (Pontes Pinto 1986:323-327). Sobre os últimos falantes de Caripuna (pano), cf. vocabulário de Faria em 1927 (Rondon \& Faria 1948:163-174). Sobre os grupos arara e caripuna (pano) do Madeira, entre o rio Abunã e o Ig. Araras, cf. comentários etnológicos 
de Macchetti em 1869 (Macchetti 1886:31-48). Sobre os Chacobo (pano), cf. viagem de Heath no Mamoré em 1880 e seu encontro com mais de 20 Chacobo que apareceram repentinamente diante da expedição, perto da foz do rio Pacaás-Novos (Heath 1882:133). Sobre os Pacahuara, Bacas e Sinabo (pano) do Mamoré nas missões espanholas do século XVIII, cf. comentários de Chávez Suárez (1986:442-444). Sobre os Pacanoa e os Pacova (pano) do século XVIII, cf. localização exata na Bolívia no mapa "Nova Luzitânia" de Pontes, assim como os comentários de Leverger (Melgaço 1884:272):

[1774] na cachoeira da Bananeira [perto de Guajará-Mirim], apareceu uma maloca de índios pacovas dando sinais de quererem aldear-se; foram enviados uns 40 de ambos os sexos e algumas crianças para a Fortaleza da Conceição [abaixo da atual cidade de Costa Marques], onde não tardaram em morrer sucessivamente.

Em 1795, o padre Negrete foi enviado na cachoeira da Bananeira pelas autoridades espanholas de Santa Cruz para fundar uma redução, no mesmo local em que Leverger descreveu, 21 anos antes, os índios pacovas. Negrete contactou 118 índios de língua pacahuara, que formavam 3 aldeias na cachoeira da Bananeira e cujos nomes foram devidamente registrados (Villar, Córdoba \& Combès 2009:126-130, 227-242). O exame minucioso desses antropônimos nitidamente pano-chacobo mostra que, no século XVIII, toda a região ribeirinha de Guajará-Mirim estava ocupada por grupos pano.

Na Bolívia, esta língua pano continua viva, especialmente entre o rio Yata e o rio Ivón, mas, no Brasil, os últimos falantes de pacahuara ou caripuna desapareceram por volta de 1930. Na mesma época, um grupo tupi-guarani apareceu no Jaci-Paraná e, como seu chefe se chamava Yaripuna, o S.P.I. (por volta de 1945) pensou ter achado novamente os famosos Caripuna desaparecidos: e foi assim que os Caripuna-Pano, mestres incontestáveis das corredeiras do Madeira desde o século XVII, ressuscitaram, por assim dizer, tornando-se Caripuna-Kawahib! Como Leonel (1995:41) notou com indignação:

A atribuição do nome caripunas aos índios cavaíbas [tupiguarani do Jaciparaná]... apenas vem mostrar, mais uma vez, a total falta de apoio etnológico em que a FUNAI mantém até hoje os sertanistas e as frentes de atração.

E a mesma coisa aconteceu com os Wari' (família chapacura) dos rios PacaásNovos e Ouro Preto, que - de Wari' - tornaram-se milagrosamente Pacaás- 
Novos, confundindo-os assim com os Pacanoa, Pacova ou Pacas do século XVIII, todos da família pano!

\subsection{Os Mequéns}

É um dos numerosos nomina nuda que se encontram no alto Guaporé do século XVIII. Não se sabe nada da língua ou da cultura deste grupo. Indicado como Moquem no mapa de Nimuendajú, com a menção "língua desconhecida", eles viviam entre o São Simão (atual rio Branco) e o Corumbiara, especialmente na área de Pedras Negras e do rio Mequéns. Em 1742, Manoel Félix de Lima desceu o rio Guaporé e, no trecho da Ilha Comprida (foz do rio Mequéns), encontrou numerosos índios guerreiros de feições formosas, que cultivavam amendoim e muito milho (Southey 1981:179-181). Em 1754, os Mequéns foram missionados na missão portuguesa de São José pelo padre Agostinho Lourenço, na foz do rio Corumbiara, juntamente com os Guarayuta. Esta missão, com o tempo, passou da foz do Corumbiara à foz do Mequéns (ou rio São José, 1756), e veio se acabar na foz do São Domingos (perto da atual cidade de Costa Marques). Apesar de parte dos Mequéns terem sido missionados, outra parte continuou livre e mansa no rio Mequéns por volta dos anos 1790 (Almeida e Serra 1857:30). No século XIX, os Mequéns não são mais mencionados, mas - exatamente na mesma região - aparecem, por sua vez, os índios palmelas, da família carib. Poderiam ser os mesmos índios (cf. Palmelas no glossário). Outros nomina nuda apareceram durante o século XVIII no São Simão (rio Branco): os Lambis, os Crutrias e os Patiti. Esses índios criavam galinhas, patos e coelhos. Os Crutrias andavam nus, furavam o nariz e as orelhas, não cortavam o cabelo. Eles tinham braceletes de algodão nos braços e nas pernas, e também usavam colares (Castelnau 1851, vol. 3:160-163). Tudo isso poderia corresponder à área cultural definida por Lévi-Strauss (1948:371-379) nos rios Branco, Mequéns e Corumbiara.

Por volta de 1950, alguns indivíduos guaratira (um grupo sakirabiat da família tupi) do rio Mequéns foram alcunhados de "índios mequéns" pelos seringueiros com os quais eles trabalhavam. No entanto, eles insistiam em dizer que eram "Guaratira" e não "Mequéns". Hoje, os Sakirabiat do rio Mequéns recusam-se a ser chamados de "Mequéns": para eles, "Mequéns" é apenas o nome do rio em que vivem. Apesar de tantas reticências, não faltam etno-historiadores imprudentes que fazem dos Mequéns do século XVIII os tupi sakirabiat de hoje, confundindo assim o etnônimo antigo com o hidrônimo, e declarando, sem a menor prova, que toda a cerâmica encontrada naquele trecho do Guaporé é tupi! 


\section{Conclusão: problemas não resolvidos e novas diretivas de pesquisa}

A bibliografia básica para a Bolívia é Chávez Suárez (1986) e Métraux (1948); para o Brasil, não há nada de comparável, fora o mapa de Nimuendajú (1987), que deve ser atualizado e corrigido.

Apesar da raridade ou da dificuldade interpretativa das fontes, resta todavia um trabalho considerável a fazer para tirar o máximo delas. O que foi dito não deve criar ilusão: quase tudo deve ser retomado e repensado. Portanto, ainda não chegou a hora de vastas sínteses do lado brasileiro. Inventários parciais, mas críticos - como Price (1983) tentou fazer - são ardentemente desejados e sempre bem vindos.

Alguns mecanismos gerais devem ser mais seriamente abordados pelos etno-historiadores: os povoamentos, as migrações, as invasões, as fortificações, o impacto das guerras tribais, a oposição entre "arawak" (agricultor sedentário) e "guarayo" (nômade caçador), as formas de segregações culturais, os contatos entre povos (alianças políticas e presença de sociedades com servos), as rupturas de unidades, etc.

Onde terminam os mitos e onde começam os fatos concretos? Os dados demográficos tirados das crônicas ou das excavações devem ser cuidadosamente examinados. Como exemplo de interpretação divergente: para Métraux (1948), 18.000 pessoas viviam na província de Mojos em 1715, mas para Denevan (1980), 112.000 pessoas viviam lá no fim do século XVII, calculando ainda 350.000 pessoas para a mesma área em 1580 !

Os limites da arqueologia não são sempre percebidos, especialmente do lado brasileiro, quando os historiadores e os linguistas pedem aos arqueólogos que fixem o proto-habitat dos povos: isso é uma tarefa às vezes aventurosa, porque é utópico acreditar que necessariamente um horizonte arqueológico da proto-história deva ser atribuído a um grupo linguístico dado. Por outro lado, a arqueologia, vista como ramo da antropologia, oferece informações valiosas sobre questões de civilização e de área cultural.

A excavação, mesmo bem executada, é apenas um começo. Ela fornece materiais apenas elaborados que só tomam seu verdadeiro significado no quadro de trabalhos de síntese. A síntese tipológica é a mais necessária: estabelecer a extensão geográfica e cronológica, assim como as variações no espaço e no tempo, de um tipo determinado de cerâmica, de enterro, de habitat, etc. A síntese regional, muito mais delicada, pede um real domínio na 
apreciação de um material complexo e só pode intervir a um nível adiantado da pesquisa. Na espera de tudo isso, queremos insistir na importância fundamental de uma cartografia precisa dos tipos e dos achados. Por enquanto, os mapas arqueológicos são feitos com lacunas e, no seu interior, alguns pontos indicando achados casuais.

\section{ANEXOS}

\section{Etnônimos do grande Madeira: alguns equívocos históricos}

A tendência geral consistiu em usar nomes antigos para etnias novas, o que era cômodo, tendo em vista a total ignorância das línguas faladas pelas antigas etnias.

\begin{tabular}{|c|}
\hline ga", "índio bárbaro", séc. XVI) $\rightarrow \rightarrow \rightarrow \rightarrow \rightarrow \rightarrow$ Guarayo (Tupi-Gu \\
\hline$\rightarrow \rightarrow \rightarrow \rightarrow \rightarrow \rightarrow \rightarrow \rightarrow \rightarrow \rightarrow \rightarrow \rightarrow \rightarrow \rightarrow \rightarrow \rightarrow \rightarrow \rightarrow \rightarrow \rightarrow \mathrm{Na}$ \\
\hline 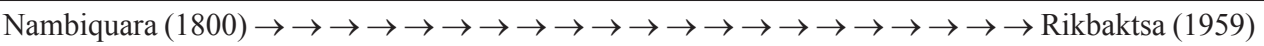 \\
\hline 27, Pareci) $\rightarrow \rightarrow \rightarrow \rightarrow \rightarrow \rightarrow \rightarrow \rightarrow \rightarrow$ Cabixi (Pareci, certos grupos chapacura, nambi \\
\hline 7) $\rightarrow \rightarrow \rightarrow ? ? \rightarrow \rightarrow \rightarrow-$ \\
\hline n, Juma (1781-1828) $\rightarrow \rightarrow \rightarrow \rightarrow \rightarrow \rightarrow \rightarrow \rightarrow \rightarrow \rightarrow \rightarrow \rightarrow \rightarrow$ Cawahib \\
\hline 1714, Pano) $\rightarrow \rightarrow \rightarrow \rightarrow \rightarrow \rightarrow \rightarrow \rightarrow \rightarrow \rightarrow \rightarrow$ Caripuna (1945, Tupi-Guarani) \\
\hline Pacova, Pacanoa (1774, Pano) $\rightarrow \rightarrow \rightarrow \rightarrow \rightarrow \rightarrow \rightarrow \rightarrow \rightarrow \rightarrow \rightarrow \rightarrow$ Pacaás-Novos (1913, Chapacura) \\
\hline \\
\hline
\end{tabular}

\section{Algumas mudanças nos topônimos fluviais}

A tendência geral consistiu em substituir o nome original por antropônimos: nomes de santos (San Martín, San Julián, São Miguel, São Domingos, etc.) ou nomes de pessoas ilustres (Roosevelt, Pimenta Bueno, etc.). Como exemplos de mudanças, aquelas efetuadas por Rondon: R. Caio Espíndola (empregado de Rondon), R. Manoel Corrêa (certo vereador), R. Eugênia (a noiva de certo capitão morto pelos índios), Pimenta Bueno (certo governador), Vilhena (certo engenheiro), Roosevelt (certo presidente), etc. O rio São Domingos (perto de Costa Marques) foi quase mudado em rio Cartucho, em homenagem a Cartucho, cãozinho de estimação do marechal Rondon que se afogou no rio São Domingos!

A etimologia popular pode tornar quase impossível a interpretação dos topônimos. Como exemplo disso, o Igarapé Pacova que se tornou com o tempo Igarapé Bananeira (abaixo da cidade de Guajará-Mirim), por mera etimologia popular entre a palavra pacovas ou pacanoa, grupo indígena 
da família pano vivendo ali, e a palavra pacova "banana" na Língua Geral da Amazônia (confira a citação de Leverger em 5.3.). No entanto, acima de Guajará-Mirim, o rio Pacaás-Novos, que se referia aos mesmos índios pacanoa, continua assim chamado até hoje, apesar de dizer etimologicamente a mesma coisa que Igarapé Bananeira!

\begin{tabular}{|l|l|}
\hline TOPÔNIMO ANTIGO & TOPÔNIMO MODERNO \\
\hline Cayari & Madeira (séc. XVII) \\
\hline $\begin{array}{l}\text { Manu, Ma(g)no, } \\
\text { Amarumayo }\end{array}$ & Madre de Dios (séc. XIX) \\
\hline Diaben, Manuema & Beni (séc. XVII) \\
\hline Himana, Manahi & Mamoré (séc. XVII) \\
\hline Guarinoca & López (perto de Guacaraje, Bolívia) \\
\hline Iraibi & Rio Blanco (Bolívia) \\
\hline Guapasce & Rio Negro (na cidade de Baure, Bolívia) \\
\hline Tahuamanu & Orton \\
\hline ??? & Ivón \\
\hline ??? & Heath \\
\hline Tacuatimanu & Rio de Las Piedras \\
\hline Ubaí & Itonama (Rio San Miguel) \\
\hline Lago Chiquiguane & Lago San Luis (perto de Magdalena, Bolívia) \\
\hline Pociçari ou Aripuanã & Aripuanã (séc. XVIII) \\
\hline Araxiá & Marmelos (séc. XVIII) \\
\hline Apitiá, Ipitiá & $\begin{array}{l}\text { Machado, Ji-Paraná ou, no alto curso, Pimenta Bueno } \\
\text { (séc. XVIII-XX) }\end{array}$ \\
\hline São Simão & $\begin{array}{l}\text { Rio Branco (afluente do Guaporé, abaixo de Pedras } \\
\text { Negras, séc. XIX) }\end{array}$ \\
\hline Castanha & Roosevelt (séc. XX) \\
\hline Cavalleiro & Corumbiara (séc. XVIII) \\
\hline $\begin{array}{l}\text { São Manuel ou } \\
\text { Paranatinga }\end{array}$ & Teles Pires, São Manuel ou Paranatinga (séc. XX) \\
\hline São Francisco & Manoel Corrêa (afluente do rio São Miguel, séc. XX) \\
\hline & \\
\hline
\end{tabular}

\section{Glossário dos etnônimos do grande Madeira}

O seguinte glossário contém as principais línguas e dialetos encontrados no "Grande Madeira". Entre colchetes, a primeira menção histórica. Seguem informações sobre a família linguística, os diversos clãs e/ou grupos, outras 
denominações, assim como uma tentativa de localizar o conjunto dialetal na sua primeira menção.

Os nomina nuda (denominações vazias ou etnônimos que aparecem laconicamente entre o século XVI e o século XX para desaparecer sem deixar vestígios linguísticos) foram, de um modo geral, descartados. Uma cruz $(\dagger)$ significa que não há mais falantes fluentes. Uma cruz pequena $\left(^{\dagger}\right)$ indica que os falantes são fluentes até um certo ponto, o que se reflete em um conhecimento linguístico insuficiente do meio-ambiente nativo (fauna e flora). Um ponto de interrogação (?) significa que não conseguimos informações atualizadas.

\section{ABITANA. Cf. Wanyam.}

AIKANÃ [1914, Nordenskiöld (1915:371-72)]. Língua isolada. Outros nomes: Massaka [antropônimo], Cassupá [antropônimo], Tubarão [antropônimo: deformação de Tubalom, nome de um índio da etnia Salamãi], Huari, Mondé. O etnônimo Tubarão, como alteração de Tubalom, é um bom exemplo de etimologia popular. Localização: Cf. Fig. 3.

AKUNSU. Um grupo dialetal sakirapiat. Cf. Sakirabiat.

AMARAKAERI. Cf. Harakmbet.

AMNIAPÉ. Cf. Sakirabiat.

AMONDAWA. Cf. Parintintin.

APIAKÁ [1746, Fonseca (1986, vol. 1:63)]. Família tupi. No rio Juruena, da confluência com o rio Arinos até o interflúvio Juruena-São Manuel (ou Teles Pires), ao sul dos Mundurucu. Parecem ter se espalhado deste interflúvio para o sul no começo do século XVIII ou antes.

APURINÃ [1854, Wilkens (1896)]. Família arawak. Margem direita do Purus entre o rio Iaco e o rio Ituxi, incluindo o rio Acre.

ARAONA [1621, Bolívar (1906:181 e ss.)]. Família takana. Do rio Manurimi (afluente do Madre de Dios) até o rio Abunã.

ARARA. Cf. Pacahuara.

†ARARA DO ARIPUANÃ [1820-1875, Souza (1875:130), Spix \& Martius (1981:276)]. Família tupi. Outros nomes: †Yugapkatã, Arara do Beiradão. No rio Aripuanã.

ARARA DO MACHADO [1714, Leite (1938, vol. 3:394)]. Família tupi. Outros nomes e grupos: Karo, Ramarama, Itogapuk (Ntogapid), Urumi. Baixo curso do rio Machado.

†ARASA. Cf. Esse-Ejja.

†ARIKAPU [1934, Snethlage (1937)]. Família Jabuti. Poderiam ser os Maxubi mencionados em 1914 por Fawcett (1953). No alto rio Branco, afluente do Guaporé.

ARIKÉM. Cf. Karitiana.

ARUÁ. Cf. Mondé.

$\uparrow$ ATSAHUACA [1902, Métraux (1948:453)]. Família pano. Outro nome: Yamiaca. Entre o rio Tambopata e o rio Inambari (afluentes meridionais do Madre de Dios).

AvA. Cf. Guarani. 
AYOREO. Cf. Zamuco.

AYURU. Cf. Wayoró.

BAKAIRI [1727, Campos (1862:448)]. Família carib. No alto curso do rio Paranatinga e nas fontes orientais do rio Arinos.

BARBADOS. Cf. Bororo.

BAURE [1595, Chávez Suárez (1986:8)]. Família arawak. Outros nomes e grupos: Maure, Muchojeón, Paikone(ka). Nos rios Blanco e San Martín (rios que desembocam no Guaporé).

BEIÇO-DE-PAU. Cf. Tapayuna.

BESIRO. Cf. Chiquito.

$\dagger$ BORORO \& UMUTINA (Barbados) [séc. XVIII]. Família bororo. Uma faixa do nordeste ao sudoeste: das cabeceiras do rio Paraguay até a Chiquitania.

CABIXI. Cf. Wanyam, Pareci, Nambiquara.

$\dagger$ CANiChanA [1675, Castillo (1906:295 e ss.)]. Língua isolada. No rio Machupo (leste do Mamoré).

CANOEIRO. Cf. Rikbaktsa.

CARIPUNA. Cf. Parintintin, Pacahuara.

CASSUPÁ. Cf. Aikanã.

CAUTÁRIO. Cf. Moré.

CAVINEÑo [1770, Armentia (1887:9)]. Família takana. No curso inferior do rio Madidi (afluente do Beni).

CAWAHIB. Cf. Parintintin, Mondé.

CAYUVAVA [1621, Bolívar (1906:181 e ss.)]. Língua isolada. No rio Mamoré, perto de Exaltación.

СНАСОво. Cf. Pacahuara.

CHАMA. Cf. Esse-Ejja.

СНAMACOCO. Cf. Zamuco.

CHANÁ. Cf. Chané.

CHANÉ [1521-36, Métraux (1963:200)]. Família arawak. Norte do Chaco: do rio Guapay (pé dos Andes) ao rio Paraguay e à fronteira argentina. Grupos: †Chané Ocidental [violentamente agredidos pelos Guarani e, com o tempo, linguisticamente guaranizados] \& Chané Oriental [antigos servos dos Guaycuru e conhecidos como Tereno, Kinikinao, Layana, Chaná, etc. Os Chané Orientais passaram ao Brasil com os Guaycuru no fim do século XVIII].

CHAPACURA. Cf. Tapacura.

CHIMANe. Cf. Moseten \& Chimane.

CHIQUiTo [1543-57, Métraux (1948:383-384), Chávez Suárez (1986:126)]. Língua isolada. Outros nomes: Chiquitano, Besiro. Ao leste do rio Guapay (rio Grande): do norte do Chaco até o curso superior do rio Paraguá, rio San Martín e rio Negro.

Chiriguano. Cf. Guarani.

CINTA LARGA. Cf. Mondé.

ČONTAKIRO. Cf. Piro. 
CORAVE(KA). Cf. Otuqui.

CuJubiM. Cf. Moré.

CURUMINA(KA). Cf. Otuqui.

DIAHOI. Cf. Parintintin.

DIGÜT. Cf. Mondé.

DJEOROMITXI [ $\approx 1910$, Snethlage (1937)]. Família Jabuti. Outro nome: Jabuti. No alto rio Branco, afluente do Guaporé.

ENAWENÊ-NAWÊ [1797, Almeida e Serra (1844:196)]. Família arawak. Outros nomes: Salumã, Saruma. No começo do século XIX: entre o rio Juruena e as cabeceiras do rio Aripuanã (Mato Grosso).

ESSE-EJJA [1567-1621, Bolívar (1906:181 e ss.)]. Família takana. Outros nomes: Guarayo, Chama, †Arasa. Entre o curso superior do rio Madidi (afluente do Beni), o rio Tambopata e o Madre de Dios.

GAVIÃo. Cf. Mondé.

†GORGOTOQUI [1547, Chávez Suárez (1986:126-127)]. Língua desconhecida (catecismo e gramática desaparecidos). Poderia ser um dialeto chiquitano. Outro nome: Corotoqui. Entre o rio Guapay e San José de Chiquitos.

GUARANI [1521-36, Métraux (1963:199), Chávez Suárez (1986:113-117)]. Família tupi. Outros nomes ou grupos dialetais na Bolívia: Ava, Chané, Izoceño, Tapieté, Simba, Chiriguano, Guarayo, †Itatim, etc. Migrando do Brasil ao pé dos Andes (séculos XV-XVI): ao sul de Santa Cruz e nos Bañados de Izozog até a Argentina (posição atual).

GUARASUGWE [1741, Fonseca (1860:398)]. Família tupi. Outros nomes: Guarayuta, Guarayo do Paucerne. Em ambas as margens do rio Guaporé, entre o rio Paraguá e o rio Paucerne (afluente do Guaporé do lado boliviano, sua foz ficando um pouco abaixo da atual cidade de Pimenteira). Ainda existem dois falantes que vivem em Pimenteira.

GUARATEGAJA. Cf. Sakirabiat.

GUARATIRA. Cf. Sakirabiat.

GUARAYO [1793, Cardús (1886:88)]. Família tupi. Outro nome: Guarayu. Ao norte de San Javier (Chiquitania): entre o rio San Pablo (San Miguel) e o rio Blanco. Cf. também EsseEjja, Guarani.

GUARAYUTA. Cf. Guarasugwe.

GUATó [1543, Cabeza de Vaca (1946:520-599)]. Língua isolada. Pantanais do interflúvio Paraguay-Cuiabá (rio São Lourenço).

GUAYCURU. Cf. Mbayá.

HALOTESU. Cf. Nambiquara.

HARAKMBET [começo do séc. XIX]. Língua isolada. Outros nomes e grupos: Mashco, Amarakaeri, Huachipaeri, Arasairi, Sapiteri, Toyoeri, etc. Entre os Andes e o Madre de Dios, do rio Pilcopata até o rio Inambari.

HUACHIPAERI. Cf. Harakmbet.

HUARI. Cf. Aikanã.

IGNACIANO. Cf. Moxo. 
IÑAPARI [ $\approx 1900$, Stiglich (1903:416)]. Família arawak. rio de las Piedras, afluente do Madre de Dios.

IRANXE, IRANCHE. Cf. Münkü.

†IRURI [1682, Betendorf (1910:355-257)]. Língua desconhecida. Grupos: Paraparixana, Aripuanã, Onicoré, Tororis. No Madeira: entre o rio Aripuanã e o rio Manicoré.

ITENE. Cf. Moré.

ITOGAPUK. Cf. Arara do Machado.

ITONAMA [1704-1713, Barnadas (2005:75)]. Língua isolada. No rio Itonama, afluente do rio Guaporé.

IZOCEÑo. Cf. Guarani.

JABUTI. Cf. Arikapu, Djeoromitxi.

JACARÉ. Cf. Pacahuara.

JARU. Cf. Urupá.

JOARI. Cf. Karitiana.

JORÁ. Cf. Sirionó.

JUMA. Cf. Parintintin.

KABIXI. Cf. Wanyam, Pareci, Nambiquara.

KADIWEU. Cf. Mbayá.

KAMPÉ. Cf. Sakirabiat.

KANOÉ [1928 (Nimuendajú), 1934 (Rondon, 1948)]. Língua isolada. Outro nome: Kapixana. Localização: Cf. Fig. 3.

KAPIXANA. Cf. Kanoé.

KARITIANA [1909, Rondon (1948:21)]. Família tupi. Outros grupos: Arikém, Joari. Localização: Cf. Fig 3.

KARO. Cf. Arara do Machado.

$\lceil$ KATAWIXI [1768(?)-1850, Wilkens (1896), Monteiro Noronha (1862)]. Possivelmente da família katukina-kanamari. Entre o Purus e o Madeira, do Mucuim ao Ituxi.

KAVINEÑo. Cf. Cavineño.

KAWAHIB. Cf. Parintintin, Mondé.

KAXARARI [1889, Ehrenreich (1891:58)]. Família pano. Entre o alto Curequetê (afluente do rio Ituxi) e o alto Marmelos (afluente do rio Abunã). Considerados durante muito tempo como um subgrupo apurinã (família arawak), a sua indubitável origem pano foi recentemente mostrada por Pickering (1973:63-66).

KAYABI [1800-1840]. Família tupi. No rio São Manuel (Teles Pires), no trecho correspondendo às cabeceiras do rio dos Peixes (perto da atual cidade de Sinop).

†KEPKIRIWAT [1913, Rondon (1948:183)]. Família tupi. Localização: Cf. Fig. 3.

KINIKINAO. Cf. Chané.

KuMANÁ. Cf. Moré.

KWAZÁ [1913, Rondon (1948:183)]. Língua isolada. No rio São Pedro, afluente do rio Pimenta Bueno. Poderiam ser os Guazaités, assinalados além das cabeceiras do Corumbiara 
em 1743 por certos bandeirantes (Fonseca, 1860:407). Os Aikanã chamam os Kwazá de Kwazaené (Voort, comunicação pessoal).

LATUNDÊ. Cf. Nambiquara.

LAYANA. Cf. Chané.

LECO [1594-1621, Bolívar (1906:181 e ss.), Chávez Suárez (1986:78), Métraux (1948:505)]. Língua isolada. Do rio Mapiri ao alto rio Beni.

MAKURAP [1934, Snethlage (1937)]. Família tupi. Localização: Cf. Fig. 3.

MAMAINDÊ. Cf. Nambiquara.

MANCHINERI. Cf. Piro.

MANOKI. Cf. Münkü.

MARUPA [1621, Bolívar (1906:181 e ss.)]. Família takana. Outro nome: Reyesano. Na margem oriental do rio Beni, entre Rurenabaque e a foz do rio Madidi.

MASHCO. Cf. Harakmbet.

MASSAKA. Cf. Aikanã.

$\nmid$ MATANAWI [1768, Monteiro Noronha (1862)]. Língua isolada. Interflúvio Madeira-Juruena. No rio Marmelos em 1875, provindo provavelmente do rio Roosevelt.

MATAUÁ. Cf. Moré.

MAUÉ [1637, Acuña (1986:89)]. Família tupi. Outro nome: Sateré-Mawé. Rios Maués, Andirá e Curiató (Mariaqua).

MAXUBI. Cf. Arikapu.

MBAYÁ [1542, Métraux (1963:200)]. Família guaykuru. Outros nomes: Kadiweu, Guaycuru. Norte do Chaco, migrando no Brasil no fim do séc. XVIII e abandonando definitivamente o Chaco.

MBYA. Cf. Sirionó.

†MEQUÉNS [1749, Fonseca (1860:388)]. Um dos numerosos nomina nuda que se encontram no alto Guaporé durante o século XVIII. Não se sabe qual língua falava este grupo. No rio Guaporé, eles viviam entre o rio Branco (São Simão) e o rio Corumbiara, especialmente na área de Pedras Negras e do rio Mequéns. Cf. Palmelas e discussão em 5.4.

MigUELENHO. Cf. Wanyam.

MONDÉ [1727 (?), 1934, Campos (1862:445), Snethlage (1937)]. Família tupi. Outros grupos dialetais: Salamãi (Sanamaica, Mondé), Aruá, Zoró \& Gavião (Digüt, Ikõro), Cinta Larga. Entre o rio Juruena (atual cidade de Juina) e o rio Branco, afluente do rio Aripuanã, ao sul dos Rikbaktsa (poderiam ser os antigos cabahiba do século XVIII, cf. discussão em 5.1.). Cf. Aikanã.

'MORÉ [1700, Barnadas (2005:65)]. Família chapacura. Outros nomes e grupos: Itene, Guarayo, Sirionó, Cautário (Captayo), Rokorono, Kumaná, Cujubim, Matauá. Ao longo do rio Guaporé entre sua foz e o rio São Miguel.

MORотосо. Cf. Zamuco.

MOSETEN \& CHIMANE [1588-1621, Bolívar (1906:181 e ss.), Métraux (1948:486)]. Língua isolada. Os Moseten: do rio Boopi (alto rio Beni) até Rurenabaque. Os Chimane: nos cursos superiores do rio Maniqui (Rapulo) e do rio Apere. 
MOVIMA [1621, Bolívar (1906:181 e ss.)]. Língua isolada. No rio Yacuma (ao oeste do rio Mamoré).

Moxo [1595, Chávez Suárez (1986:8)]. Família arawak. Outros nomes e grupos: Mojeño, Trinitario, Ignaciano. No rio Mamoré, entre a foz do rio Yacuma e a foz do rio Yapacani.

MUNDURUKU [ $\approx 1660$, cf. os Ururucus de Betendorf (1910:168) e de Heriarte (1975:179)]. Família tupi. Outros nomes e grupos: †Ururucu, †Jaguaim, Curubaya, Parintintin, †Urupá(?). Baixo Tapajós até o Cururu e, ulteriormente (século XVIII), atrás de Borba (rio Madeira, rio Canumã e rio Abacaxis).

MÜNKÜ [ $\approx 1900$, Rondon (1948:20)]. Língua isolada. Outros nomes e grupos: Iranche, Manoki. Ao oeste do rio do Sangue (afluente do Juruena).

MURA-PIRAHÃ [1714, Leite (1938, vol. 3:394)]. Língua isolada. No rio Madeira, perto da foz do rio Marmelos.

NAMBIQUARA [1769, Castelnau (1851, tomo 3:167)]. Família Nambikwara. Grupos: Halotesu, Latundê, Mamaindê, Tawandê, Sabanê, †Kabixi, etc. Dos rios Galera e Juina até a atual cidade de Vilhena.

NAPE(KA). Cf. Tapacura.

ORO MON, ORO WARAM, ORO NAO', ORO AT, ORO EO', ORO JOWIN. Cf. Wari'.

ORO WIN [ $\approx 1963]$. Família chapacura. Outro nome: Oro Towati. No alto rio Pacaás Novos.

†OTUQUI [séc. XVIII]. Família bororo. Grupos: Covare(ka), Curumina(ka). No leste da Chiquitania.

PACAHUARA [1681, Saavedra (1906:84)]. Família pano. Outros nomes e clãs: Pacaguara, Pacanagua, Bacanaguas, Pacas, Bacas, Chacobo, Sinabo na Bolívia; Pacanoa, Pacanova, Pacova, Cayaripuna, Caripuna, Jaunabo, Jacaré, Pama (?) no Brasil. O leitor não confundirá os Pacahuara com os †Pacanáwa (rio Envira, Acre), igualmente da família pano, e os Pacaás-Novos ou Wari' (Rondônia), da família chapacura, equívoco que - infelizmente - foi frequentemente repetido nos últimos anos. Divididos em numerosos clãs: Chacobo, Kanabo ou Arara, Kapïbo ou Jacaré, Šïnabo ("clã da lagarta"), Šašobo ("clã da canoa") etc., a localização exata de cada grupo pacahuara é extremamente delicada, devido a antigos conflitos clânicos, a guerras com os povos takana e a desintegração provocada por doenças introduzidas pelos conquistadores europeus. Citando Armentia (1887:42-43), CréquiMontfort \& Rivet (1913d:21) argumentam corretamente que os Pacahuara ocupavam antigamente uma área maior que se restringiu por causa do avanço da família takana. Podemos nos perguntar se os grupos arawak do Purus não são igualmente responsáveis por certos movimentos migratórios dos Pacahuara. Localização no século XVII: do Beni e baixo Madre de Dios até o Mamoré, o Madeira (trecho das cachoeiras) e o Abunã. Com suas elegantes canoas, os Pacahuara dominavam a navegação do Mamoré e do Madeira (das imediações da atual cidade de Porto Velho até a foz do Guaporé), e um desses grupos pano - os Cayaripuna ou Caripuna - já era mencionado acima da foz do Jamari em 1714 (Leite, 1938, vol.3:393-394).

PACANOA, PACAÁS-NOVOS, PACOVA, PACAS. Cf. Pacahuara, Wari'.

$\lceil$ PAICONE(CA) [1560, Métraux (1948:384)]. Família arawak. Um grupo baure ao norte da Chiquitania.

PAÍTER. Cf. Suruí. 
$\dagger$ PAlMelas $[\approx 1800$, Fonseca (1986, pp.190-192)]. Família carib. Ao norte de Pedras Negras (rio Guaporé). Em 1877, o General Fonseca passou por Pedras Negras e faz a primeira descrição dos índios palmelas. Esses índios foram batizados de "Palmelas" por ser este nome a denominação que o governador Luiz Pinto escolheu no século XVIII para o lugar de Pedras Negras. O vocabulário que Fonseca recolheu mostra que o palmelas é uma língua nitidamente carib. Esses índios viviam na cordilheira dos Parecis, do lado brasileiro, atrás de Pedras Negras e até o rio Mequéns. Eram índios mansos, entre eles alguns verdadeiramente brancos, como os Herisobocone e os Arara do baixo Xingu. Plantavam milho e amendoim, e criavam galinhas e patos. De onde provinham? Fonseca diz que os índios não conheciam sua procedência original. Depois de ter fugido e ter sido dispersados, teriam vivido em uma missão de fronteira (S. Miguel ou S. Simão?) e, nos anos 1800, vieram estabelecer-se atrás de Pedras Negras. Sobre os †Herisobocono, Barnadas (2005:120) disse: “[em 1754, os índios das missões jesuíticas] desalojaram os Heriseboconos de nossas fronteiras, forçando-os a retirar-se em lugares remotos das matas". Embora ninguém tenha notado palavra alguma, o herisobokono teria sido uma forma de moré falado em 1767 em San Ignacio ou em San Borja, provavelmente como índios deportados do Guaporé. Os Palmelas poderiam ser os Herisobocono ou os Mequéns do século XVIII. Cf. Mequéns.

PARECI [1599, Maurtua (1906:184)]. Família arawak. Outros nomes: Parechi, cabixi. Na Chapada dos Parecis: ao norte da linha traçada entre Diamantino e as cabeceiras do rio Juina, até a terra dos Enawenê-Nawê.

PARINTINTIN [1820, entre Canumã e Marmelos (Spix \& Martius, 1981:276)]. Família tupi. Outros nomes: Cawahib, Tenharim, Diahoi, Uru-Eu-Wau-Wau, Amondawa, Juma, Caripuna, Piripikura (Borboleta). Provindo do interflúvio Madeira-Tapajós (dos rios Canumã e Aripuanã até as fontes do rio Maués), esses grupos expandiram-se para o sul a partir do fim do século XVIII. Os Juma já são mencionados atrás de Borba em 1780-1790.

PAUCERNe, PAUCERNA. Cf. Guarasugwe.

PAUMARI. Cf. Purupurus.

'PAUNA(CA) [1595-1707, Métraux (1948:396)]. Família arawak. Ao norte de Concepción (Chiquitania).

PAWUMWA. Cf. Wanyam.

$\dagger$ PAYAGUÁ [1527, Métraux (1963:224)]. No rio Paraguay, entre as atuais cidades de Corumbá e Assunção. Juntos com os Mbayá, os Payaguá mataram milhares de portugueses e espanhóis nos séculos XVI-XVIII.

PIRAHÃ. Cf. Mura-Pirahã.

PIRIPIKURA. Cf. Parintintin.

PIRO [1686, Izaguirre (1922-29, 1:254-289)]. Família arawak. Outros nomes e grupos: Yine, Čntakiro, Manchineri, Canamari, Cuniba. No alto Purus: entre o Rio Branco (Acre) e a cidade de Atalaia (rio Ucayali).

'PURUBORÁ [1924, Rondon]. Família tupi. Localização: Cf. Fig. 3.

PURUPURUS [1714, Leite (1938, vol. 3:393)]. Família arawá. Outro nome: Paumari. Do baixo Purus até acima da foz do rio Ituxi. Provavelmente mencionado por Acuña (1986:81) em 1637 com o nome de Curucuru.

QUITEMO(KA). Cf. Tapacura. 
RAMARAma. Cf. Arara do Machado.

REYESANO. Cf. Marupa.

RIKBAKTSA [ $\approx 1800]$. Língua isolada. Entre o Rio Aripuanã e o rio Juruena, da cachoeira de Todos os Santos no Juruena ( $18^{\circ}$ lat. S.) para o sul. No século XIX, expandiram-se para o sul até o rio Arinos e o rio do Sangue, com o nome de Nambiquara (= orelha-de-pau) $[<$ tupi-guarani: nambi "orelha", quara "buraco"].

ROKORONO. Cf. Moré.

SABANÊ. Cf. Nambiquara.

SAKIRABIAT [1934, Snethlage (1937)]. Família tupi. Outros nomes e grupos: Sakïrap, Kampé, Guaratira [antropônimo], Guarategaja [antropônimo], Amniapé, Akunsu, Mequéns. A última denominação não é reconhecida pelos índios sakirabiat que vivem dentro da Reserva Mequéns ("Mequéns" é nome de rio). No entanto, em 1950, alguns grupos sakirabiat foram chamados de "mequéns" por seringueiros do Guaporé, o que gerou - na cabeça de certos etno-historiadores ou arqueólogos atuais - um equívoco que consistiu em confundir imprudentemente os Sakirabiat com os Mequéns do século XVIII. Os antigos mequéns viviam na beira do Guaporé e poderiam ser os Palmelas. (Cf. Mequéns, Palmelas).

SALAMÃI. Cf. Mondé.

SALUMã. Cf. Enawenê-Nawê.

? SAN SIMONIANOS [1870, Cardús (1886:285)]. Um dialeto chiquitano. Na Serrania de San Simón, perto da foz do rio Paraguá (afluente do rio Guaporé).

†SARAVE(CA) [1560, Métraux (1948:384)]. Família arawak. Entre Santa Ana (Chiquitania) e Vila Bela do Guaporé (Mato Grosso).

SATERÉ-MAWÉ. Cf. Maué.

SINABO. Cf. Pacahuara.

SIRIONÓ [1675, Castillo (1906:295-296)]. Família tupi. Outros nomes e grupos dialetais: Mbya, Yuiqui (Yuqui), Chori, Jorá, †Guarayo. Faixa única e uniforme do rio Yapacani (no sul) ao rio San Pablo (Mata Grande de San Pablo), até El Carmen e o Lago San Luis ao norte. Como nota justamente Cardús (1886:280): "Não obstante a grande extensão de terreno que ocupam, os Sirionos não são tão numerosos, como parece que deveriam e poderiam ser. Como não cultivam a terra, e como todos vivem somente de caça, pesca e frutas silvestres, por necessidade têm que viver en frações pequenas, apartados uns de outros, e mudar com frequência de lugar, e esta é a razão por que, sem ser tão numerosos, vê-se esses índios em tantos e tão distintos pontos". A primeira menção encontra-se em 1675 em Castillo (1906:295), que situa os Sirionó no rio Yapacani (ao oeste de Santa Cruz) com a denominação de Guarayo (são os atuais Yuqui). Mesma confusão com o padre Barace que, atravessando o Monte Grande de San Pablo ("Mata de San Pablo"), de Trinidad a Baure em 1693, encontra índios que ele chama uma vez de Sirionó (Lettres édifiantes et curieuses, 1780-83, vol. 8:105) e outra vez de Guarayo (Chávez Suárez, 1986:236-237).

SURUí [1948]. Família tupi. Outro nome: Paiter. Localização: Cf. Mondé na Fig. 3.

TACANA [1539-1621, Bolívar (1906:181 e ss.), Métraux (1948:441), Armentia (1887:14)]. Família takana. Entre o Beni, o rio Tuichi e o curso superior do rio Madidi (afluente do Beni). Cf. Araona, Cavineño, Esse-Ejja, Marupa. 
†TAPACURA [1580-83, Chávez Suárez (1986:151)]. Família chapacura. Outros nomes: Guarayo, Chapacura, Quitemo(ka), Nape(ka). No curso superior do rio Blanco (coafluente do Guaporé, com o San Martín), até suas cabeceiras.

TAPAYUNA [1747-1800]. Família jê. Outro nome: Beiço-de-pau. Frequentemente referidos como Xavante, Xerente ou Coroado (Castelnau, 1851:117), os Tapayuna viviam ao norte do rio dos Peixes, entre o Juruena e o São Manuel (rio Teles Pires), região onde alternam o cerrado e a floresta.

TAPIETÉ. Cf. Guarani.

TAWANDÊ. Cf. Nambiquara.

TENHARIM. Cf. Parintintin.

TERENo. Cf. Chané.

†TORÁ [1714, Leite (1938, vol. 3:394)]. Família chapacura. No rio Maici (divisa RondôniaAmazonas).

TOROMONA [1567-1621, Bolívar (1906:181 e ss.), Métraux (1948:441)]. Família takana. Entre o curso superior do rio Madidi (afluente do Beni) e as cabeceiras do rio Manurimi (afluente do Madre de Dios).

TRINITARIO. Cf. Moxo.

TUBARÃO. Cf. Aikanã.

TUPARI [1934, Snethlage (1937)]. Família tupi. Localização: Cf. Fig. 3. Cf. também Sakirabiat, Wayoró.

†TUPINAMBÁ [1637, Acuña (LXIX)]. Família tupi. Ilha de Tupinambarana (Parintins).

UMUTINA. Cf. Bororo.

UOMo. Cf. Wanyam.

URU-EU-WAU-WAU. Cf. Parintintin.

URUMI. Cf. Arara do Machado.

†URUPÁ [1750]. Família chapacura. Outro grupo: Jaru. Nos afluentes do rio Machado (rio Jaru e rio Urupá).

†WANYAM [1908, Haseman (1912)]. Família chapacura. Outros nomes: Miguelenho, Pawumwa, Uomo, Abitana, Kabixi. No rio São Miguel.

WARI' [1912-1941, Rondon (1948:21)]. Família chapacura. Outros nomes: Oro Wari', Pacaás-novos, Pacaa Novas. São 7 grupos: Oro Mon, Oro Waram, Oro Waram Xijein, Oro Nao', Oro At, Oro Eo', Oro Jowin. Entre o rio Pacaás Novos e o Ig. do Laje.

WAYORÓ [1934, Snethlage (1937)]. Família tupi. Outro nome: Ayuru. Ao leste dos Makurap. YAMIACA. Cf. Atsahuaca.

YAMINAHUA [ $\approx 1936$, no rio Tahuamanu vindo do alto Purus ou fugindo do Yaco]. Família pano. Outros nomes: Yora, Nahua. Nos cursos superiores do rio de Las Piedras (Bolívia), rio Tahuamanu (Bolívia), rio Acre (Bolívia, Brasil) e rio Yaco (Brasil, Bolívia).

YINE. Cf. Piro.

YORA. Cf. Yaminahua.

YUGAPKATÃ. Cf. Arara do Aripuanã. 
YUQUI. Cf. sirionó.

YURACARÉ [1573, Combès (2010:342-343)]. Língua isolada. Do Yapacani ao Chapare, afluentes do Mamoré.

ZAMUCO [1561-1585, 1711, Combès (2010:40, 210-211), Métraux (1963:241)]. Família zamuco. Grupos: Ayoreo, Chamacoco, Morotoco. Nordeste chaquenho.

zORó. Cf. Mondé.

\section{Famílias linguísticas}

A seguir, apresento as famílias linguísticas encontradas no Grande Madeira, com seus ramos e suas línguas, vivas ou extintas. Entre colchetes, a data muito aproximativa da proto-língua, obtida por extrapolação com o que se sabe do proto-indo-europeu. A noção de "dialeto", para designar variedades lexical e gramaticalmente próximas entre si, nos pareceu aqui essencial, especialmente quando esses dialetos ocupam áreas contíguas no espaço, o que poderia ter intensificado as interações linguísticas e os empréstimos entre os dialetos e, portanto, falsificar as classificações tradicionais, baseadas em dados lexicais ou em feixes de inovações fonéticas ou fonológicas.

Certos agrupamentos entre famílias foram recentemente sugeridos como, por exemplo, uma superfamília que juntaria o harakmbet, o katukinakanamari e o katawixi, ou também a superfamília macro-jê (chiquito, jabuti, rikbaktsa, jê, etc.). Tais agrupamentos não serão desenvolvidos nesta apresentação.

\section{Arawá [2.000 anos]}

Fora da área em estudo, salvo alguns grupos paumari que atingem os afluentes do Madeira ao oeste dele (interflúvio Purus-Madeira), a família arawá poderia ser melhor classificada se tivéssemos mais dados sobre o zorowaha. Note a inconsistência do etnônimo yamamadi, aplicado a duas línguas bem distintas durante os últimos decênios, sem que nenhum linguista retifique o erro: o yamamadi perto de Lábrea, que é uma forma de yarawara, e o yamamadi falado perto da Boca do Acre e no rio Inauini, que é um dialeto deni.

I) PAUMARI (Purupuru)

II) ZOROWAHA

III) YARAWARA-DENI

III') YARAWARA (yamamadi)

III') MADIHA

III $\left.{ }^{\text {ba }}\right)$ KULINA

III ${ }^{\text {bb }}$ ) DENI (yamamadi) 


\section{Arawak (Aruak, Maipure) [4.500 anos]}

Três ramos arawak são discutidos neste trabalho: Purus, Bolívia e Mato Grosso, com o total de dez línguas. A distribuição atual das línguas arawak da Bolívia sugere a intrusão de vários povos (Chiquito, Tupi-Guarani) durante os 2.000 últimos anos. O estudo dos empréstimos sugere uma origem setentrional para as línguas arawak do Mato grosso.

I) JAPURÁ-COLÔMBIA: Baniwa-Curripaco, Warekena, Yukuna, Piapoco, Kaixana, Resigaro, etc. II) †BARÉ-GUINAU

III) ALTO ORINOCO: Baniva-Maroa \& Yavitero, $†$ Maipure.

IV) NEGRO-RORAIMA: $\uparrow$ Bahuana, $\uparrow$ Manáo, Wapixana, Mawayana, etc.

V) †MARAWÁ

VI) $†$ WARAIKU

VII) CHAMICURO

VIII) PURUS [2.200 anos, 3 línguas]

VIII') PIRO

VIII') IÑAPARI

VIII') APURINÃ

IX) KAMPA (Pré-andino)

X) AMUESHA (Yanesha)

XI) BOLÍVIA [2.500 anos, 4 línguas]

$\mathrm{XI}^{\mathrm{a}}$ ) NORTE (BAURE)

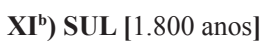

$\mathrm{XI}^{\text {ba }}$ ) CHIQUITOIDE ('PAUNA)

$\mathrm{XI}^{\mathrm{b}}$ ) MAMOREOIDE [1.200 anos]

$\mathbf{X I}^{\text {baa }}$ ) MOJEÑO (2 dialetos próximos): Trinitario, Ignaciano.

$\left.\mathrm{XI}^{\mathrm{bbb}}\right) \dagger$ CHANÉ de SANTA CRUZ, TERENO

\section{XII) CARIBEÑO}

XII ${ }^{\mathrm{a}}$ ) ORIENTAL: Lokono, Iyeri, Taino.

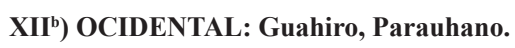

XIII) PALIKUR

XIV) MATO-GROSSO [2.000 anos]

XIVa) PARECI (3 dialetos divergentes): Pareci, Enawene-Nawe, $\uparrow$ Sarave.

XIV $\left.^{b}\right)$ XINGU (2 línguas bastante próximas): Yawalapiti, Waurá-Mehinaku.

\section{Carib [2.500 anos]}

Somente representada, na área em estudo, pelos Palmelas (alto Guaporé) e pelos Bakairi. Apesar de sua posição geográfica, o palmelas pertence à subfamília cariboide, mostrando aparentemente mais afinidades com o wai-wai e o hixkaryana. Por falta de dados, o fpimenteiras não está nesta classificação. 
I) PANARE

II) YEKUANA

III) CARIBOIDE: $†$ Palmelas, Wai-Wai, Kari’na, Waimiri-Atroari, Macuxi, Tiriyó, Yukpa, $†$ Opon, etc.

IV) ARARA-IKPENG

V) BAKAIRI

VI) XINGU (Kuikuro, Kalapalo)

Chapacura [1.500 anos, cf. Fig. 4]

Jabuti [1.500 anos]

I) DJEOROMITXI

II) ${ }^{\dagger} \mathrm{ARIKAPU}$

\section{Jê [3.000 anos]}

Somente representada, na área em estudo, pelos Tapayuna (ramo kayapó), entre o Juruena e o São Manuel.

I) KAINGANG

II) †JAIKÓ

III) JÊ CENTRAL

III) XAVANTE

III') KAYAPÓ

\section{Katukina-Kanamari}

I) KATUKINA-KANAMARI

II) $\dagger$ KATAWIXI

\section{Nambikwara [2.500 anos]}

I) SABANÊ

II) NAMBIKWARA

II') NORTE

II $)$ SUL

\section{Takana [1.500 anos]}

\section{Pano [1.500 anos]}

Por apresentarem muitas semelhanças linguísticas (o que foi salientado desde 1921), juntamos aqui as famílias pano e takana. No entanto, o tipo de relação entre esses dois grupos ainda não está bem claro: empréstimos entre duas famílias ou uma só família? Note que o estudo das línguas pano começou em 1888 e, durante mais de um século, viu-se o surgimento das classificações mais aberrantes encontradas na América do Sul. Felizmente, o estudo de Lanes (2005) pôs o fim a essas fantasias linguísticas. Essas famílias são divididas em 3 subfamílias. Entre os problemas ainda a resolver: na família takana, o ramo cavineño deve ser ligado ao ramo takana central ou - levando em conta os contatos e os empréstimos - ele formaria uma 
verdadeiramente terceira ramificação? Na família pano, qual é a posição exata do caxibo, língua que opera a transição linguística entre o pano central, o kaxarari, o matis e o matsés?
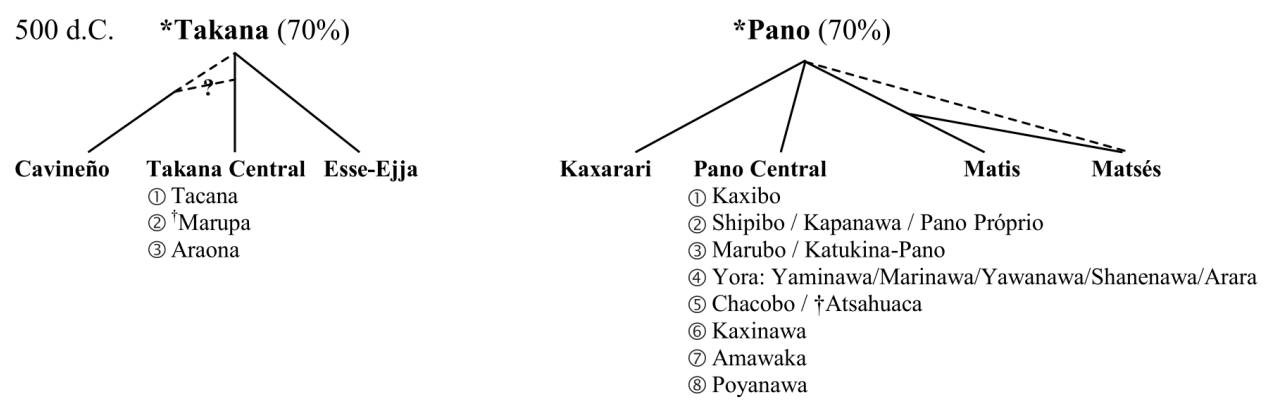

\section{Tupi [4.500 anos]}

Família muito bem representada no interflúvio Madeira-Tapajós. Certas línguas da família tupi (†kepkiriwat, 'puruborá) são mortas ou moribundas, e os dados disponíveis são insuficientes. No entanto, tentamos incluí-las nesta classificação. O †yugapkatã (arara do Aripuanã) foi também incluído nesta família, apesar da escassez de dados linguísticos. À primeira vista, parece ser a língua mais divergente da família tupi. O yugapkatã foi às vezes considerado como membro do ramo mondé por causa de uma amostra vocabular recolhida com Dona Nazaré, pessoa que não era yugapkatã, mas cativa zoró-mondé desde pequena.

I) JURUNA

II) MUNDURUKU-GUARANI

II $\left.{ }^{a}\right)$ MUNDURUKU: Munduruku \& Kuruaya.

II $\left.^{\mathrm{b}}\right)$ MAWÉ-AWETI-GUARANI

II $^{\text {ba }}$ TUPI-GUARANI (com muitos dialetos próximos: Parintintin, Apiaká, Kayabi, $\dagger$ Tupinambá, Guarani, Guarayo, Guarasugwe etc., certos sendo bem divergentes, como o Sirionó)

II $^{\text {bb) }}$ AWETI

II $\left.{ }^{\mathrm{bc}}\right)$ MAWÉ

III) TUPARI-MAKURAP (incluindo possivelmente o †KEPKIRIWAT)

III') MAKURAP

III') TUPARI (3 línguas): Tupari, Wayoró, Sakirabiat.

IV) MONDÉ-RAMARAMA-PURUBORÁ

IVa) MONDÉ

IVaa) SURUí

IVab) MONDÉ (vários dialetos: Salamãi, Aruá, Cinta larga, Zoró / Gavião)

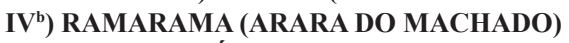

IV $\left.^{c}\right)$ †PURUBORÁ

V) ARIKÉM-KARITIANA

VI) †YUGAPKATÃ (ARARA DO ARIPUANÃ)

Famílias com membro único (línguas isoladas):

- No pé dos Andes: Yuracaré, Moseten-Chimane, Leko, Harakmbet. 
- Entre o Beni e o Guaporé: †Canichana, Itonama, Cayuvava, Movima, Chiquitano.

- No interflúvio Madeira-Tapajós: Mura-Pirahã, $†$ Matanawi, Münkü, Rikbaktsa, Aikanã, Kwazá, Kanoé.

\section{Referências}

Acuña, Cristobal de. 1986. "Nuevo Descubrimiento del Gran Rio del Amazonas (1637)”. In: Informes de jesuitas en el Amazonas (1660-1684). Iquitos, Monumenta Amazónica.

Aguire Achá, José. 1933. La antigua provincia de Chiquitos. La Paz, Editorial Renacimiento.

Almeida e Serra, Ricardo Franco. 1844. Extracto da descripção geographica da Provincia de Mato Grosso... [1797]. Revista do Instituto Histórico e Geográfico Brasileiro 6.

Almeida e Serra, Ricardo Franco. 1857. Novo diário do Rio Madeira [1790]. Revista do Instituto Histórico e Geográfico Brasileiro 20.

Armentia, Nicolás de. 1887. Navegación del Madre de Dios. La Paz, Biblioteca Boliviana de Geografía e Historia.

Armentia, Nicolás de. 1905. Relación de las Misiones franciscanas de Apolobamba. La Paz.

Azara, Félix de. 1962. Descripción del Paraguay y del Rio de la Plata [1809]. In: Manuel Ballesteros-Gaibrois (org.), Viajes por América del Sur, vol. 2:331-497. Madrid, Aguilar (Bibliotheca Indiana, 4).

Barnadas, Josep e M. Plaza. 2005. Mojos: seis relaciones jesuíticas (16701763). Cochabamba, Historia Boliviana.

Bayle, Constantino. 1951. Las Misiones, defensa de las fortalezas de Mainas. In: Missionalia Hispanica, pp. 417-503.

Bettendorf, João de. 1910. Chronica da missão dos padres da companhia de Jesus no Estado de Maranhão [1669]. Revista do Instituto Histórico e Geográfico Brasileiro 72.

Block, David. 1980. In search of El Dorado (1550-1767). Tese de doutorado, Universidade de Austin, Texas.

Block, David. 1997. La cultura reduccional de los Llanos de Mojos. Sucre.

Bolívar, Gregorio. 1906. Relación de la entrada del Padre... a la provincia de los indios Chunchos en 1621. In: Colección de documentos que apoyan el alegato de Bolivia en el Juicio Arbitral con la República del Perú. Buenos Aires.

Cabeza de Vaca. 1946. Comentarios. Madrid.

Cabral, Octaviano. 1963. Histórias de uma região. Niterói, Editora Himalaya. 
Campos, Antonio Pires de. 1862. Breve notícia... [1727]. Revista do Instituto Histórico e Geográfico Brasileiro 25:437-449.

Cardús, José. 1886. Las Misiones Franciscanas entre los Infieles de Bolivia. Descripción del estado de ellas en 1883 e 1884. Barcelona, Librería de la Inmaculada Concepción.

Castelnau, Francis de. 1851. Expédition dans les parties centrales de l'Amérique du Sud (1842). Paris, Chez P. Bertrand.

Castillo, José. 1906. Relación de la Provincia de Mojos [1675]. In: Manuel Vicente Ballivian, Documentos para la historia geográfica de la República de Bolivia. La Paz.

Chávez Suárez, José. 1986. Historia de Moxos. La Paz, Editorial Don Bosco.

Combès, Isabelle. 2010. Diccionario étnico. Santa Cruz la Vieja y su entorno en el siglo XVI. Cochabamba, Instituto de Misionología.

Créqui-Montfort e Paul Rivet. 1913a. Linguistique bolivienne. La famille linguistique Čapacura. Journal de la Société des Américanistes 10:118-171. Paris.

Créqui-Montfort e Paul Rivet. 1913b. Linguistique bolivienne. La langue Saraveka. Journal de la Société des Américanistes 10:497-540. Paris.

Créqui-Montfort e Paul Rivet. 1913c. Linguistique bolivienne. La langue Kanichana. Mémoires de la Société de Linguistique de Paris 18:354-377. Paris.

Créqui-Montfort e Paul Rivet. 1913d. Linguistique bolivienne. Les dialectes pano de Bolivie. Le Muséon 14:19-78. Paris.

Denevan, William. 1966. The aboriginal cultural geography of the Llanos de Mojos of Bolivia. Berkeley, Universidade da Califórnia.

Ehrenreich, Paul. 1891. Beiträge zur Völkerkunde Brasiliens. In:

Veröffentlichungen aus dem königlichen Museum für Völkerkunde, tomo II, pp 1-80. Berlin.

Faden, William. 1807. Mapa (feito sobre mapas do século XVIII).

Fawcett, Percy Harrison. 1953. Exploration Fawcett. Londres, Hutchinson.

Fonseca, José Gonçalves da. 1860. Navegação desde o Pará até o rio Madeira, 19/II/1749. In: Cândido Mendes de Almeida, Memórias, pp. 367-400.

Fonseca, João Severiano. 1986. Viagem ao redor do Brasil (1875-1878). Rio de Janeiro.

Gama Malcher, José M. 1964. Índios: grau de integração na comunidade nacional, grupo linguístico, localização. Rio de Janeiro, Conselho Nacional de Proteção aos Índios.

Gandia, Enrique. 1935. Historia de Santa Cruz de la Sierra. Buenos Aires.

Haseman, J. D. 1912. Some notes on the Pawumwa of South America. American Anthropologist 14:333-349. 
Heath, E.R. 1882. The exploration of the River Beni. Journal of the American Geographical Society of New York 14:117-165.

Heriarte, Maurício. 1975. Descrição do Estado do Maranhão, Pará, Corupa e rio das Amazonas (1662). In: Francisco Varnhagen, História Geral do Brasil, vol. III:171-180. São Paulo, Melhoramentos.

Holanda Pereira, Adalberto. 1994. O pensamento mítico do Rikbaktsa. Pesquisas, Antropologia, ${ }^{\circ}$ 50. São Leopoldo, Instituto Anchietano de Pesquisas.

Hugo, Vitor. 1959. Os desbravadores. 2 volumes. Missão Salesiana de Humaitá. Izaguirre Ispizua, Bernardino. 1922-29. Historia de las misiones franciscanas y narración de los progresos (1619-1921). Lima.

Labre. 1889. Coronel Labre's explorations in the region between the Beni and Madre de Dios Rivers and the Purus. Proceedings of the Royal Geographical Society 11:496-502. Londres.

Lanes, Elder. 2005. Aspectos da mudança linguística: as línguas Pano. Tese de doutorado, Universidade Federal de Rio de Janeiro.

Leite, Serafim. 1938-43. História da Companhia de Jesus no Brasil. 4 volumes. Lisboa.

Leonel, Mauro. 1995. Etnodicéia Uruéu-au-au. São Paulo, Editora da Universidade de São Paulo.

Lettres édifiantes et curieuses, éscrites des missions étrangères, par quelques missionnaires de la Compagnie de Jésus (1780-83). 26 vols. Paris.

Lévi-Strauss, Claude. 1948. Tribes of the right bank of the Guaporé river. In: J. Steward (ed.), Handbook of South American Indians, vol. 3:361-379. Washington, Bureau of American Ethnology.

Loukotka, Čestmir. 1968. Classification of South American Indian languages. University of California.

Macchetti, Fray Jesualdo. 1886. Diario del viaje fluvial del Padre Fray Jesualdo Macchetti, misionero del Colegio de La Paz, desde San Buenaventura y Reyes hasta el Atlántico en 1869. La Paz, El Siglo Industrial.

Maldi Meireles, Denise. 1983. Populações indígenas e a ocupação histórica de Rondônia. Monografia de especialização, Universidade Federal de Mato Grosso.

Maldi Meireles, Denise. 1989. Guardiões da fronteira: rio Guaporé, século XVIII. Petrópolis, Editora Vozes.

Maroni, Pablo. 1988. Noticias auténticas del famoso Río Marañón (1738). Iquitos, Monumenta Amazónica.

Maúrtua, Víctor M. 1906. Juicio de límites entre Perú y Bolivia. Tomo X. Madrid. 
Melgaço, Barão de. 1884. Apontamentos chronologicos da província de Matto Grosso. Revista do Instituto Historico e Geographico do Brasil 48. Rio de Janeiro.

Menendez, Miguel A. 1998. A área Madeira-Tapajós. In: Manuela Carneiro da Cunha (org.), História dos índios no Brasil, pp. 281-296. São Paulo, Companhia das Letras.

Métraux, Alfred. 1928. La civilisation matérielle des tribus tupi-guarani. Paris, Librairie Orientaliste.

Métraux, Alfred. 1948. The tribes of Eastern Bolivia and the Madeira headwaters. In: J. Steward (ed.), Handbook of South American Indians, vol. 3:349-360, 381-506. Washington, Bureau of American Ethnology.

Métraux, Alfred. 1963. Ethnography of the Chaco. In: J. Steward (ed.), Handbook of South American Indians, vol. 1:197-241. Washington, Bureau of American Ethnology.

Miller, Eurico Theofilo. 1983. História da cultura indígena do alto-médio Guaporé. Dissertação de mestrado, Pontifícia Universidade Católica do Rio de Janeiro.

Montaño Aragón, Mario. 1987-92. Guía etnográfica y lingüística de Bolívia (3 volumes). La Paz, Editorial Don Bosco.

Monteiro Noronha, José. 1862. Roteiro da viagem do Pará até as últimas colônias do sertão (1768). Pará.

Nimuendajú, Curt. 1924. Os índios Parintintin do Rio Madeira (1924), Journal de la Société des Américanistes 16:46-110. Paris.

Nimuendajú, Curt. 1948. The Cawahíb, Parintintin and their neighbors. In: J. Steward (ed.), Handbook of South American Indians, vol. 3:283-297. Washington, Bureau of American Ethnology.

Nimuendajú, Curt. 1987. Mapa etno-histórico. Rio de Janeiro, IBGE.

Nordenskiöld, Erland. 1915. Forskningar och äventyr i Sydamerika [19131914]. Stockholm, Albert Bonniers Förlag.

Orbigny, Alcide D. d'. 1944. El hombre americano. Buenos Aires, Editorial Futuro.

Pickering, Wilbur. 1973. Vocabulário Kaxararí. Série Linguística 1:63-66, Summer Institute of Linguistics. Brasília.

Pontes, Antônio Pires da Silva. 1798. Nova Luzitania (mapa).

Pontes Pinto, Emanuel. 1986. Caiari: lendas, proto-história e história. Rio de Janeiro.

Price, David. 1983. Pareci, Cabixi, Nambiquara: a case study in the western classification of native peoples. Journal de la Société des Americanistes 49. Paris.

Ramirez, Henri. 2001. Línguas Arawak da Amazônia setentrional. Manaus, Universidade Federal do Amazonas. 
Ribeiro de Sampaio, Francisco Xavier. 1985. As viagens do Ouvidor Sampaio (1774-1775). Manaus, Associação Comercial do Amazonas.

Riester, Juergen. 1977. Los Guarasug’we: crónica de sus últimos días. La Paz, Editorial Los Amigos del Libro.

Rodrigues, Aryon D. 1964. A classificação do tronco linguístico Tupi. Revista de Antropologia 12.1/2:99-104.

Rondon, Cândido M.S. 1916. Lectures delivered by... Publications of the Rondón Commission, n 43:192 ff. Rio de Janeiro.

Rondon, Cândido M.S. e J. Barbosa de Faria. 1948. Glossário Geral das tribos silvícolas de Mato-Grosso e outras da Amazônia e do Norte do Brasil. Tomo I. Rio de Janeiro, Imprensa nacional.

Saavedra, Bautista. 1906. Defensa de los derechos de Bolivia ante el Gobierno Argentino en el litigio de fronteras con la República del Perú. Tomo II. Buenos Aires.

Snethlage, Emil Heinrich. 1935. Nachrichten über die Pauserna-Guarayú, die Siriono am Río Baurés und die San Simonianes in der Nähe der Serra San Simón. Zeitschrift für Etnologie 67:278-293. Berlin.

Snethlage, Emil Heinrich. 1937. Atiko-y: Meine Erlebnisse bei den Indianern des Guaporé. Berlin.

Southey, Robert. 1981. História do Brasil, vol. 3. São Paulo, Editora Itatiaia.

Souza, Francisco Bernardino de. 1875. Comissão do Madeira, Pará e Amazonas. Rio de Janeiro, Typographia Nacional.

Spix, Johann Baptist von e Carl von Martius. 1981. Viagem pelo Brasil (18171820), vol. 3. Belo Horizonte, Editora Itatiaia.

Steinen, Karl von den. 1894. Unter den Naturvölkern Zentral-Brasiliens. Berlin.

Stiglich, Germán. 1903. La región peruana de los bosques. Colección de documentos oficiales referentes a Loreto 15:308-495. Lima.

Torres, Manuel Rodrigues. 1738. Relatório a D. João V (30:6/1738). Lisboa, Arquivo Histórico Ultramarino.

Villar, Diego, Lorena Córdoba e Isabelle Combès. 2009. La reducción imposible: las expediciones del Padre Negrete a los Pacaguaras (17951800). Cochabamba, Instituto de Misionología.

Voort, Hein van der. 2004. A grammar of Kwaza. Berlin, Mouton de Gruyter.

Wilkens de Mattos, João. 1896. Alguns esclarecimentos sobre as missões da Província do Amazonas (1855). Revista do Instituto Historico e Geographico Brasileiro 19. 